\title{
Plant natural products for cognitive impairment: A review of the preclinical evidence
}

\author{
Helmi Helmi ${ }^{1}$, Nanang Fakhrudin ${ }^{2 *}$, Arief Nurrochmad ${ }^{3}$, Zullies Ikawati ${ }^{3}$ \\ ${ }^{1}$ Faculty of Pharmacy, Universitas Gadjah Mada, Yogyakarta, Indonesia. \\ ${ }^{2}$ Department of Pharmaceutical Biology, Faculty of Pharmacy, Universitas Gadjah Mada, Yogyakarta, Indonesia. \\ ${ }^{3}$ Department of Pharmacology and Clinical Pharmacy, Faculty of Pharmacy, Universitas Gadjah Mada, Yogyakarta, Indonesia.
}

\begin{tabular}{l}
\hline ARTICLE INFO \\
\hline Received on: 06/02/2021 \\
Accepted on: 29/03/2021 \\
Available online: 05/06/2021 \\
\\
\hline Key words: \\
Cognitive enhancer, herbal \\
medicine, memory loss, \\
nootropics, secondary \\
metabolites.
\end{tabular}

\section{INTRODUCTION}

Cognition, an exclusive function of the brain, is the sum total of mental activities involved in thinking, reasoning, learning, and memory regulation. Impairment of this function is well known as cognitive impairment (CI) disease (Deture and Dickson, 2019; Johansson et al., 2015). This condition is characterized by impairment in attention and focus, calculation ability, decisionmaking, thinking, and memory. $\mathrm{CI}$ is a complex and progressive disease caused by many factors. Many studies describe aging as a major risk factor in CI. The prevalence of CI was reported to increase linearly with increasing age $(19.2 \%$ at $65-74$ years old, $27.6 \%$ at $75-84$ years old, and $38 \%$ at 85 years or older). There are more than 16 million people in the USA with CI, and almost 5.1 million have Alzheimer's disease (AD), the most common type of

\footnotetext{
${ }^{*}$ Corresponding Author

Nanang Fakhrudin, Department of Pharmaceutical Biology, Faculty of Pharmacy, Universitas Gadjah Mada, Yogyakarta, Indonesia. E-mail:nanangf@ugm.ac.id
}

CI. This number is predicted to be tripled or around 152 million people in 2050, especially in low- and middle-income countries (Li et al., 2020; Richardson et al., 2019).

The incidence of $\mathrm{CI}$ is also associated with several serious and mental diseases, such as $\mathrm{AD}(8.2 \%)$, stroke or cerebrovascular diseases $(5.7 \%)$, and alcohol abuse $(1.5 \%)$. The mortality rate of $\mathrm{CI}$ is $8 \%$, and it tends to increase annually. Although stroke and $\mathrm{AD}$ are the two diseases with the fastest annual progression ( $20 \%$ and $17 \%$, resp.), the annual progression of CI to dementia is still high (11.7\%). In addition, CI has many negative impacts on health status, independence, and socioeconomic aspects of human beings. $\mathrm{CI}$ is considered as a high-cost illness from a socioeconomic perspective. Previous clinical studies in the USA reported that $\mathrm{AD}$ and dementia are the third most expensive diseases, costing approximately nine times more than other diseases. Globally, the costs of AD and dementia reached as much as US\$ 2 trillion in 2030 (Rizzi et al., 2014). Thus, a therapeutic approach preventing or curing $\mathrm{CI}$ is crucial to maintain and even increase the health status of the global community. To date, the clinical effectiveness of conventional drugs for the treatment of 
CI (e.g., tacrine, donepezil, rivastigmine, and galantamine) is still limited. These drugs failed to provide consistent efficacy across all cases of CI. Moreover, undesirable side effects (e.g., nausea, vomiting, hepatotoxicity, and diarrhea) often accompanied the main therapeutic effect in long-term medication (Mehta et al., 2012; Sharma et al., 2019; Tiwari et al., 2019). This emphasizes the need for discovering alternative therapeutic agents for CI with high efficacy and minimal side effects.

One of the potential sources of agents to prevent or cure neurodegenerative diseases is medicinal plants. Plants provide bioactive natural compounds with wide structural diversity that might match the therapeutic targets of CI and other neurological disorders (Lautie et al., 2020). Many studies have been conducted to explore the potential of medicinal plants for the treatment of CI using different targets and mechanisms of action. Additionally, some studies demonstrated the chemical constituents responsible for the activity of such plants and their therapeutic targets. The mechanisms underlying the pharmacological effects to explain how the phytochemical constituents exert their effects were also reported.

In this review article, we summarize the cognitiveenhancing effects of plant natural compounds from preclinical studies. The therapeutic targets or modes of action in the context of CI are also discussed in this article. To provide a scientific basis for CI therapy and a better understanding of the therapeutic targets, the pathophysiology of CI was also briefly introduced.

\section{Pathophysiology of CI}

Previous studies suggested that several abnormal conditions of the central nervous (CNS) are strongly correlated with the pathology of CI in humans (Adams et al., 2017; Mufson et al., 2012). We have summarized these with an emphasis on the four conditions explained below as a suggested model of the underlying mechanism of CI pathophysiology (Fig. 1).

\section{Aging and CI}

Aging is a natural physiological process closely related to decreased human quality of life and increased complex disease risk factors, including neurodegenerative disorders. The majority of elderly people demonstrate a decrease in the endogenous immune system and antioxidant systems. These conditions lead to inflammatory reactions, aging, and oxidative stress, which cause impairment of brain neurons (Fard and Con, 2019).

\section{Amyloid beta $(A \beta)$ and tau proteins in $C I$}

$\mathrm{A} \beta$ plaque is a toxic protein and represents a hallmark of $\mathrm{AD}$. This insoluble protein is a product of amyloid precursor protein (APP) degradation by the enzyme secretase. The three types of $A \beta$ protein are $A \beta$ monomer, dimer, and oligomer Among them, the oligomer $A \beta$ is the most toxic to the brain. The oligomer $\mathrm{AB}$ can reside in several regions of the brain, such as the basal ganglia, thalamus, hypothalamus, medulla oblongata, and cerebellum. Additionally, neurofibrillary tangles (NFT), a misfolded form of tau protein, are also found and can lead to CI and other brain diseases. In the normal condition, tau protein is a substantial protein that plays a role in the stabilization of the microtubules of neurons. This protein is part of the neuron and responsible for maintaining nutrients and transporting substances required by the brain. The accumulation of $A \beta$ plaque and NFT in the temporal and frontal cortex regions leads to synaptic dysfunction and further provokes $\mathrm{CI}$ in the patients with $\mathrm{AD}$ via oxidative stress and neuroinflammatory mechanisms (Deture and



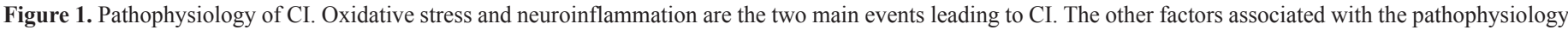

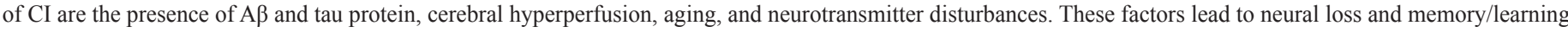
deficits leading to $\mathrm{CI}$. 
Dickson, 2019; Tönnies et al., 2017; Kent et al., 2020; Tiwari et al., 2019).

\section{Cerebral hypoperfusion and CI}

CI is commonly found in poststroke and/or traumatic brain injury conditions. Hemodynamic abnormalities, particularly in cerebral hypoperfusion, are associated with neurodegeneration in these conditions. Hypoperfusion of the cerebri causes imbalances of endogenous reactive oxygen species/nitrite oxygen species (ROS/NOS)-antioxidant systems and leads to oxidative brain injury. This condition activates microglia to release a number of proinflammatory cytokines and induces a severe neuronal loss in the brain (Liu and Zhang, 2012).

\section{Neurotransmitter disturbances and CI}

Disturbances in acetylcholine (ACh), serotonin (5HT), dopamine (DA), and glutamate (Glu) neurotransmitters contribute to memory and learning deficiencies and cause CI. Decreasing ACh, $5 \mathrm{HT}$, and DA levels in the brain are closely correlated with AD and Parkinson's disease. The low level of these neurotransmitters in the brain is caused by aberrations in their production located in the presynapse and/or by degradation in the synaptic junction. This condition interferes with the transmission of nerve impulses and impairs cognitive functional signaling pathways. In contrast to the neurotransmitters mentioned previously, high levels of Glu induce calcium neuroexcitotoxicity through persistent activation of N-methyl-d-aspartate acid (NMDA) and $\alpha$-amino-3-hydroxy5-methylisoxazole propionic acid receptors and cause neuronal damage (Yunqi et al., 2013).

\section{Oxidative stress and neuroinflammation as a major pathogenetic mechanism of $C I$}

Imbalances of the endogenous antioxidant system are reported as one of the major causes of progressive neurodegenerative diseases. In this case, overproduction of ROS/ NOS causes oxidative stress that triggers lipid peroxidation and induces neuronal damage in the brain (Tönnies and Trushina, 2017). Neuroinflammation is the body's response to the accumulation of $\mathrm{A} \beta$ plaque and is recognized as a common feature of AD. Neuroinflammation is considered as a key factor in the pathogenesis and progression of AD. Neuroinflammation is initiated by the activation of microglia, which induces the release of proinflammatory cytokines, such as IL-6 and tumor necrosis factor alpha (TNF $\alpha)$ (Kinney et al., 2018). An understanding of the pathophysiology of neuroinflammation is crucial for identifying potential therapeutic targets in the effort to discover and develop cognitive-enhancing drugs.

\section{Potential therapeutic targets in CI}

There are four potential therapeutic targets for the prevention and treatment of CI. These therapeutic targets are shown in Figure 2.

\section{Neurotransmitter modulators}

The common target of cognitive function-enhancing drugs is the inhibition of cholinesterase (ChE) and monoamine oxidase enzymatic activity, as well as the inhibition of the enzymes responsible for $\mathrm{ACh}$ and monoamine neurotransmitter degradation.

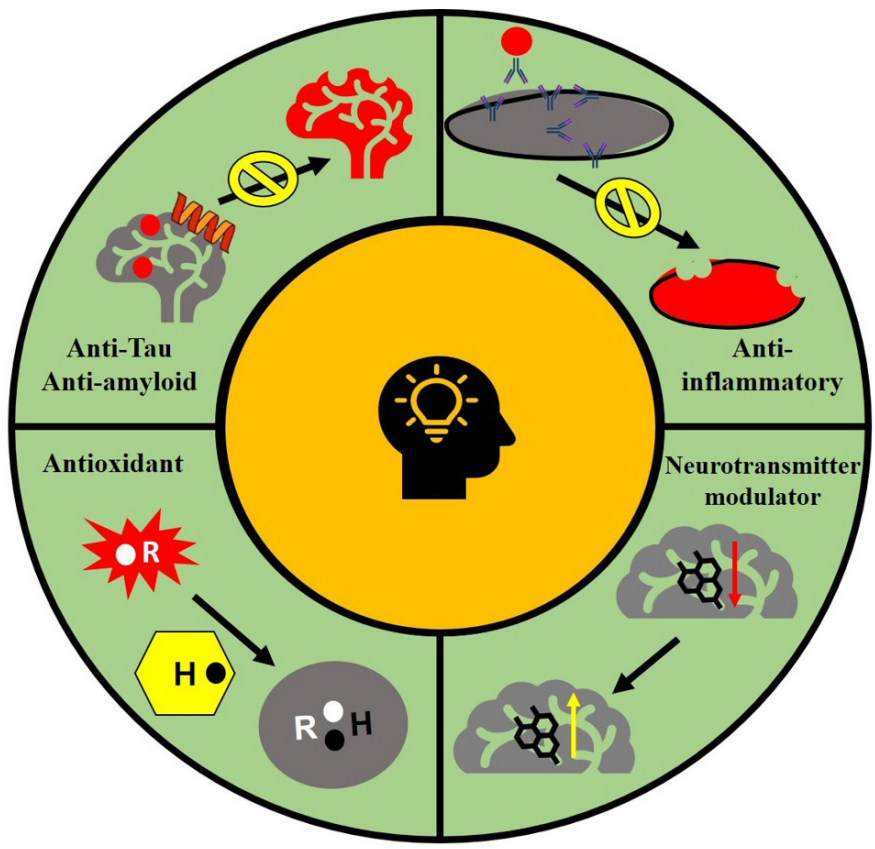

Figure 2. Potential therapeutic targets in CI. Antioxidant, anti-inflammatory, antitau, antiamyloid, and neurotransmitter modulator represent the promising therapeutic target of plant natural products for combating CI.

These so-called "neurotransmitter modulator" drugs effectively increase intracellular levels of ACh, 5HT, and DA. In memory and learning ability, neurotransmitter modulators are required to initiate neurotransmitter-receptor binding postsynapse, which stimulates various cellular and molecular signal transductions to improve cognitive function, regulation, and maintenance (Ferreira-Vieira et al., 2016; Hampel et al., 2020; Stanciu et al., 2019). Interestingly, drugs that antagonize ChE and NMDA are ineffective at stopping the progression of CI. However, the clinical use of these drugs is proven to be effective at improving cognitive performance and other symptoms of CI only for a short time period (Moss, 2020; Yaari and Ann, 2015).

\section{Antiamyloidogenic}

Antiamyloidogenic is a term to describe a group of drugs or substances that inhibit $\mathrm{A} \beta$ plaque formation, aggregation, and fibrillation, as well as promoting $A \beta$ plaque degradation and clearance. Antiamyloidogenic agents act by downregulating $\beta$ and $\gamma$-secretase and upregulating $\alpha$-secretase enzyme activity. The decrease in $A \beta$ plaque accumulation potentially reduces the risk of neuroinflammation, which represents the main factor causing AD. Antiamyloidogenic drugs are a relatively novel and promising approach for the treatment of $\mathrm{AD}$ and other forms of dementia. The development of these drugs is challenging, especially in the clinical trial stage (Yaari and Ann, 2015). Although the therapeutic approach targeting $\mathrm{A} \beta$ production and deposition is a promising hypothesis, none of the clinical trials so far succeeded in developing effective and safe therapeutic agents. The clinical outcome of this agent is determined by various factors that affect its efficacy and safety. These factors include the intrinsic factors such as polarity and molecular size that dictate the ability to cross the blood-brain barrier and the extrinsic factors such as the genetics of patients, 
severity of illness, and neuropathology. The clinical trials of the agents targeting $A \beta$ such as lanabecestat, semagacestat, verubecestat, atabecestat, aducanumab, bapineuzumab, solanezumab, crenezumab, and gantenerumab have failed due to the lack of efficacy and the emergence of toxic effects (Abushakra et al., 2017; Tolar et al., 2020; Oxford et al., 2020).

\section{Antioxidant agents}

The consumption of dietary supplements comprising antioxidative agents is an appropriate approach to overcoming endogenous antioxidant system imbalances and/or insufficiencies. Antioxidants are required to improve the body's defense system to prevent neuronal loss due to lipid peroxidation in the brain. They prevent the loss of neuron and synapse degeneration in the median temporal lobe, hippocampus, and cortex. Thus, decreases in neurotransmitter levels in the brain can be avoided. Intake of antioxidant compounds can protect the brain from the oxidative damage associated with AD. Antioxidants directly or indirectly inhibit ROS/NOS formation and modulate the activity and expression of endogenous antioxidants. Many studies have demonstrated that the consumption of polyphenol compounds with antioxidant activity is associated with a lower risk and slower progression of AD (Colizzi, 2019).

\section{Anti-inflammatory drugs}

The efficacy of nonsteroidal anti-inflammatory drugs (NSAIDs) for improving $\mathrm{CI}$ in $\mathrm{AD}$ is still a matter of debate. Preclinical evidence revealed that the use of NSAIDs is a promising therapeutic approach for the prevention and treatment of AD. As mentioned earlier, chronic neuroinflammation is a wellknown attribute of $\mathrm{AD}$ and is involved in its pathogenesis. The underlying mechanism of this drug is related to the inhibition of neuroinflammatory progression upon the occurrence of $A \beta$ plaques and NFT in the brain. However, the administration of anti-inflammatory drugs showed modest efficacy, and this effect is inconsistent in the clinical context. NSAIDs effectively reduce the risk of $\mathrm{AD}$ and dementia, but only in the early stage of the diseases (Imbimbo et al., 2010). A recent clinical investigation showed that the use of several NSAIDs, especially diclofenac, was associated with a reduction of the prevalence and progression rate of $\mathrm{CI}$ in AD (Imbimbo et al., 2010; Stuve et al., 2020).

\section{Potential natural cognitive enhancers from plants}

Medicinal plants have been used traditionally to treat cognitive-related diseases, including cognitive disorders. The long history of drug development from natural products proves that many natural compounds of plant origin have inspired the discovery of new drug entities or "lead compounds" (Achilonu and Dennis, 2015; Rahimi et al., 2010). For example, physostigmine isolated from Physostigma venenosum seeds demonstrated parasympathomimetic activity in the human CNS system. Physostigmine was the first drug candidate for the treatment of AD and parasympathetic-related diseases, such as myasthenia gravis and glaucoma. Unfortunately, this development was hampered by strong scientific evidence indicating that physostigmine has a narrow therapeutic index and a short duration of action and shows undesired side effects, such as abdominal colic, nausea, vomiting, hypersalivation, and hyperhidrosis. Later, the chemical structural modification of physostigmine resulted in the development of the new drug entities epastigmine and fenserine. Another example of a promising natural compound for the treatment of $\mathrm{AD}$ is galantamine, an alkaloid isolated from the bulb of Galanthus nivalis. Galantamine potently inhibited AChEI and showed efficacy against AD (Hermann, 2015; Mehta et al., 2012).

Nowadays, drug discovery efforts are drawing major attention by focusing on the identification of bioactive compounds of plant origin, including those for cognitive function-enhancing drugs (Benek et al., 2020). A cognitive function enhancer, also known as a nootropic or "smart drug," is a synthetic and/or natural substance that is used to improve cognitive functions. This drug is widely used for the treatment of neurodegenerative diseases, and it effectively enhances cognition aspects in patients with $\mathrm{AD}$ and other cognitive function-related disorders affecting memory, learning ability, motivation, attention, and focus. Several natural compounds that have been tested for cognitive function-enhancing activity in an amnesic-animal model are presented in Table 1.

Table 1 shows that scopolamine-induced memory loss in rodents is the most popular bioassay used by researchers for evaluating cognitive function-enhancing effects. Scopolamine is a muscarinic receptor antagonist that acts by blocking the central cholinergic system and the nervous system. Blockade of this system leads to CI (especially in learning and memory ability), which is the hallmark of AD (Balmus and Ciobica, 2017; Blokland et al., 2016; Jivad and Rabiei, 2014; Prashar et al., 2014). Additionally, scopolamine is well known as a potent inducer of ROS/NOS in the upregulation of proinflammatory cytokines in the CNS (Haider et al., 2016). These conditions trigger neuronal damage leading to $\mathrm{AD}$. Based on the bioactive compound variability presented in Table 1, we clustered the active compounds on the basis of their chemical structure. Figure 3 shows that the chemical classes of the active compounds are very diverse, ranging from simple to complex. Interestingly, flavonoids are the most frequently reported compounds for enhancing cognitive function, followed by terpenoids and alkaloids.

A flavonoid is a secondary metabolite compound with a C6-C3-C6 backbone. Flavonoids are widely distributed in plants and have various biological activities. Although most flavonoids show antioxidant activity due to the presence of hydroxyl groups (Brodowska, 2017; Kumar and Abhay, 2013), some flavonoids (e.g., curcumin, ellagic acid, genistein, kolaviron, luteolin, myricetin, oroxylin A, quercetin, resveratrol, trans-cinnamaldehyde, vitexin, and mangiferin) exert cholinomimetic activity and block the cholinergic system. Flavonoids reduce oxidative stress and inflammation and might thus lower the risk of memory impairment. These lines of evidence suggest that flavonoids are promising natural compounds for further development as drugs for AD. Other flavonoids, such as hesperidin, rutin, anthocyanins, naringin, and silibinin, are the most reported flavonoids tested for their therapeutic value in $\mathrm{AD}$ using in vivo models (de Andrade Teles et al., 2018).

\section{Multitarget action of natural compounds for CI}

Many studies have demonstrated the multitarget actions of herbal medicines and their metabolites, which is important for drug discovery and development efforts (Bizzarri et al., 2020). A multitarget drug is a new perspective on modern 
Table 1. Natural compounds with potential cognitive function-enhancing activity evaluated in amnesic-animal models.

\begin{tabular}{|c|c|c|c|c|c|c|}
\hline Compounds & $\begin{array}{l}\text { Plant/dietary } \\
\text { sources }\end{array}$ & Test doses & Animal models & $\begin{array}{l}\text { Behavioral } \\
\text { tests }\end{array}$ & Actions & Ref \\
\hline$\alpha$-Amyrin & Angelica keiskei & $\begin{array}{l}0.5 ; 1 ; 2 ; 4 \mathrm{mg} / \\
\mathrm{kg} / \mathrm{day}\end{array}$ & $\begin{array}{l}\text { Scopolamine }(1 \mathrm{mg} / \mathrm{kg} / \mathrm{day}) \\
\text { induced } \mathrm{CI} \text { in male mice }\end{array}$ & PAT & $\begin{array}{l}\alpha \text {-Amyrin improved memory impairment by inducing } \\
\text { ERK and GSK- } 3 \beta \text { phosphorylation in the hippocampus. }\end{array}$ & $\begin{array}{l}\text { (Park et al., } \\
\text { 2014) }\end{array}$ \\
\hline$\alpha$-Pinene & Thuja orientalis & $\begin{array}{l}3 ; 10 \mathrm{mg} / \mathrm{kg} / \\
\text { day }\end{array}$ & $\begin{array}{l}\text { Scopolamine }(1 \mathrm{mg} / \mathrm{kg} / \text { day }) \\
\text { induced learning and memory } \\
\text { impairment in C } 57 \mathrm{BL} / 6 \text { mice }\end{array}$ & $\begin{array}{l}\text { YM, } \\
\text { MWM, } \\
\text { PAT }\end{array}$ & $\begin{array}{l}\alpha \text {-Pinene improved memory, learning, and cognitive } \\
\text { function by increasing ChAT expression in the cortex } \\
\text { and inducing enzymatic antioxidant (HO-1, manganese, } \\
\text { and SOD) level expression in the hippocampus. }\end{array}$ & $\begin{array}{l}\text { (Lee et al., } \\
\text { 2017) }\end{array}$ \\
\hline$\beta$-Amyrin & A. keiskei & $\begin{array}{l}0.5 ; 1 ; 2 ; 4 \mathrm{mg} / \\
\mathrm{kg} / \text { day }\end{array}$ & $\begin{array}{l}\text { Scopolamine }(1 \mathrm{mg} / \mathrm{kg} / \text { day }) \\
\text { induced } \mathrm{CI} \text { in male mice }\end{array}$ & PAT & $\begin{array}{l}\beta \text {-Amyrin improved memory impairment by inhibiting } \\
\text { AChE activity and inducing ERK and GSK-3 } \beta \\
\text { phosphorylation in the hippocampus. }\end{array}$ & $\begin{array}{l}\text { (Park et al., } \\
\text { 2014) }\end{array}$ \\
\hline Acteoside & $\begin{array}{l}\text { Callicarpa } \\
\text { dichotoma }\end{array}$ & $\begin{array}{l}0.1 ; 1 ; 2,5 \mathrm{mg} / \\
\mathrm{kg} / \text { day }\end{array}$ & $\begin{array}{l}\text { Scopolamine }(1 \mathrm{mg} / \mathrm{kg} / \text { day }) \\
\text { induced amnesia in male mice }\end{array}$ & $\begin{array}{l}\text { PAT, } \\
\text { MWM }\end{array}$ & $\begin{array}{l}\text { Acteoside increased long-term and/or short-term spatial } \\
\text { memory formation. The mechanism is unclear, but } \\
\text { it might target the cholinergic system and act as an } \\
\text { antioxidant. }\end{array}$ & $\begin{array}{l}\text { (Lee et al., } \\
2006)\end{array}$ \\
\hline Aloe emodin & Rheum officinale & $\begin{array}{l}25 ; 50 ; 100 \\
\mathrm{mg} / \mathrm{kg} / \mathrm{day}\end{array}$ & $\begin{array}{l}\text { Scopolamine }(2 \mathrm{mg} / \mathrm{kg} / \mathrm{day}) \\
\text { induced memory impairment } \\
\text { in male mice }\end{array}$ & MWM & $\begin{array}{l}\text { Aloe emodin improved cognitive deficit by inhibiting } \\
\text { AChE activity and modulating oxidative stress } \\
\text { conditions (increasing SOD and GSH-Px activities and } \\
\text { decreasing the MDA level) in the hippocampus. }\end{array}$ & $\begin{array}{l}\text { (Tao et al., } \\
\text { 2014) }\end{array}$ \\
\hline Arctigenin & Arctium lappa & $3 \mathrm{mg} / \mathrm{kg} /$ day & $\begin{array}{l}\text { Male APP/PS1 transgenic } \\
\text { mice as an AD model }\end{array}$ & MWM & $\begin{array}{l}\text { Arctigenin reversed memory impairment by inhibiting } \\
\mathrm{A} \beta \text { production (by targeting BACE1 expression and } \\
\text { enhancing } \mathrm{A} \beta \text { clearance via AKT/mTOR signaling and } \\
\text { AMPK/Raptor signaling pathways). }\end{array}$ & $\begin{array}{l}\text { (Zhu et al., } \\
\text { 2013) }\end{array}$ \\
\hline \multirow[t]{2}{*}{ Ascorbic acid } & $\begin{array}{l}\text { Fruits and } \\
\text { vegetables }\end{array}$ & $125 \mathrm{mg} / \mathrm{kg} /$ day & $\begin{array}{l}\text { Scopolamine }(1 \mathrm{mg} / \mathrm{kg} / \text { day }) \\
\text { induced memory impairment } \\
\text { in APP/PSEN1 transgenic } \\
\text { mice }\end{array}$ & $\begin{array}{l}\text { LAT, } \\
\text { ZM, YM, } \\
\text { MWM }\end{array}$ & $\begin{array}{l}\text { Ascorbic acid improved learning and memory } \\
\text { impairment via a mechanism related to its antioxidant } \\
\text { capacity and glutamatergic neurotoxicity protection } \\
\text { activity. }\end{array}$ & $\begin{array}{l}\text { (Harrison } \\
\text { et al., 2009) }\end{array}$ \\
\hline & & $\begin{array}{l}60 ; 120 \mathrm{mg} / \\
\mathrm{kg} / \text { day }\end{array}$ & $\begin{array}{l}\text { Scopolamine }(0.4 \mathrm{mg} / \mathrm{kg} / \text { day }) \\
\text { and diazepam }(1 \mathrm{mg} / \mathrm{kg} / \text { day }) \\
\text { induced CI in young and aged } \\
\text { Swiss mice }\end{array}$ & EPM, PAT & & $\begin{array}{l}\text { (Parle and } \\
\text { Dinesh, } \\
\text { 2003) }\end{array}$ \\
\hline Berberine & Coptis chinensis & $\begin{array}{l}100 ; 500 \mathrm{mg} / \\
\mathrm{kg} / \text { day }\end{array}$ & $\begin{array}{l}\text { Scopolamine }(1 \mathrm{mg} / \mathrm{kg} / \text { day }) \\
\text { induced amnesia in male } \\
\text { Sprague Dawley rats }\end{array}$ & PAT, MAT & $\begin{array}{l}\text { Berberine demonstrated an antiamnesic effect, but the } \\
\text { mechanism remained unknown. It might target the } \\
\text { peripheral and central cholinergic nervous systems. }\end{array}$ & $\begin{array}{l}\text { (Peng et al., } \\
1997 \text { ) }\end{array}$ \\
\hline Crocin & $\begin{array}{l}\text { Crocus sativus } \\
\text { Gardenia } \\
\text { jasminoides }\end{array}$ & $\begin{array}{l}7.5 ; 15 ; 30 \mathrm{mg} / \\
\mathrm{kg} / \text { day }\end{array}$ & $\begin{array}{l}\text { D-galactose }(400 \mathrm{mg} / \mathrm{kg} / \text { day }) \\
\text { induced aging model in male } \\
\text { Wistar rats }\end{array}$ & MWM & $\begin{array}{l}\text { Crocin enhanced spatial and learning memory functions } \\
\text { by acting as an antiglycation (decreasing CML } \\
\text { expression) and antioxidative (decreasing MDA level) } \\
\text { agent. It also suppressed brain inflammatory mediators } \\
\text { (IL-1, TNF, and NF- }{ }_{\mathrm{K}} \mathrm{B} \text { ) and modulated the PI3K/AKT } \\
\text { and ERK/MAPK signaling pathways. }\end{array}$ & $\begin{array}{l}\text { (Heidari } \\
\text { et al., 2017) }\end{array}$ \\
\hline Cryptotanshinone & $\begin{array}{l}\text { Salvia } \\
\text { miltiorrhiza }\end{array}$ & $\begin{array}{l}2.5 ; 5 ; 10 ; 20 \\
\mathrm{mg} / \mathrm{kg} / \text { day }\end{array}$ & $\begin{array}{l}\text { Scopolamine }(1 \mathrm{mg} / \mathrm{kg} / \mathrm{day}) \\
\text { induced memory impairment } \\
\text { in male mice }\end{array}$ & PAT & $\begin{array}{l}\text { Cryptotanshinone ameliorated memory and learning } \\
\text { deficit by inhibiting AChE activity. }\end{array}$ & $\begin{array}{l}\text { (Kim et al., } \\
\text { 2007) }\end{array}$ \\
\hline Curcumin & Curcuma longa & $200 \mathrm{mg} / \mathrm{kg} /$ day & $\begin{array}{l}\text { Heavy (4 Gy carbon) ion } \\
\text { irradiation-induced memory } \\
\text { and learning deficit in mice }\end{array}$ & MWM & $\begin{array}{l}\text { Curcumin reversed spatial learning and memory decline } \\
\text { by modulating brain oxidative stress (increased SOD } \\
\text { activity and decreased MDA level) and upregulating } \\
\text { Nrf } 2 \text { protein and its downstream genes (NQO-1, HO-1, } \\
\text { and } \gamma \text {-GCS) in the brain. }\end{array}$ & $\begin{array}{l}\text { (Xie et al., } \\
2014)\end{array}$ \\
\hline $\begin{array}{l}\text { 15,16- } \\
\text { Dihydrotanshinone I }\end{array}$ & S. miltiorrhiza & $\begin{array}{l}0.5 ; 1 ; 2 ; 4 \mathrm{mg} / \\
\mathrm{kg} / \text { day }\end{array}$ & $\begin{array}{l}\text { Scopolamine }(1 \mathrm{mg} / \mathrm{kg} / \text { day }) \\
\text { induced memory impairment } \\
\text { in male mice }\end{array}$ & PAT & $\begin{array}{l}\text { 15,16-Dihydrotanshinone I ameliorated memory and } \\
\text { learning deficit by inhibiting AChE activity }\end{array}$ & $\begin{array}{l}\text { (Kim et al., } \\
\text { 2007a) }\end{array}$ \\
\hline $\begin{array}{l}\text { Docosahexaenoic } \\
\text { acid }\end{array}$ & Seafood and algae & $\begin{array}{l}200 ; 300 \mathrm{mg} / \\
\mathrm{kg} / \text { day }\end{array}$ & $\begin{array}{l}\text { Scopolamine }(1 \mathrm{mg} / \mathrm{kg} / \mathrm{day}) \\
\text { induced memory impairment } \\
\text { in male Albino mice }\end{array}$ & $\begin{array}{l}\text { MWM, } \\
\text { EPM, }\end{array}$ & $\begin{array}{l}\text { Docosahexaenoic acid enhanced spatial memory only } \\
\text { in the scopolamine-treated group but not in the normal } \\
\text { group. The exact mechanism of action is not yet } \\
\text { elucidated in this study but may be related to free-radical } \\
\text { scavenging activity. }\end{array}$ & $\begin{array}{l}\text { (Saroj and } \\
\text { Tulika, } \\
\text { 2018) }\end{array}$ \\
\hline Echinocystic acid & $\begin{array}{l}\text { Codonopsis } \\
\text { lanceolata }\end{array}$ & $\begin{array}{l}10 ; 20 \mathrm{mg} / \mathrm{kg} / \\
\text { day }\end{array}$ & $\begin{array}{l}\text { Scopolamine }(1 \mathrm{mg} / \mathrm{kg} / \mathrm{day}) \\
\text { induced memory impairment } \\
\text { in male mice }\end{array}$ & $\begin{array}{l}\text { PAT, YM, } \\
\text { MWM }\end{array}$ & $\begin{array}{l}\text { Echinocystic acid prevented memory impairment by } \\
\text { inhibiting AChE activity and inducing pCREB and } \\
\text { BDNF expression. }\end{array}$ & $\begin{array}{l}\text { (Kim et al., } \\
\text { 2007a) }\end{array}$ \\
\hline \multirow[t]{2}{*}{ Ellagic acid } & $\begin{array}{l}\text { Berries, nuts, } \\
\text { seeds, and } \\
\text { vegetables }\end{array}$ & $\begin{array}{l}10 ; 30 ; 100 \\
\mathrm{mg} / \mathrm{kg} / \mathrm{day}\end{array}$ & $\begin{array}{l}\text { Scopolamine }(0.4 \mathrm{mg} / \mathrm{kg} / \text { day }) \\
\text { and diazepam- }(1 \mathrm{mg} / \mathrm{kg} / \text { day }) \\
\text { induced memory deficit in } \\
\text { male Wistar rats and mice }\end{array}$ & $\begin{array}{l}\text { EPM, OFT, } \\
\text { PAT }\end{array}$ & $\begin{array}{l}\text { Ellagic acid prevented memory impairment by inhibiting } \\
\text { AChE activity and promoted the antioxidative defense } \\
\text { system (decreased MDA level and increased GSH, SOD, } \\
\text { and catalase activity). }\end{array}$ & $\begin{array}{l}\text { (Mansouri } \\
\text { et al., 2016) }\end{array}$ \\
\hline & & $\begin{array}{l}25 ; 50 \mathrm{mg} / \mathrm{kg} / \\
\text { day }\end{array}$ & $\begin{array}{l}\text { Scopolamine }(0.7 \mathrm{mg} / \mathrm{kg} / \\
\text { day) induced Alzheimer's } \\
\text { type memory and cognitive } \\
\text { dysfunction in male Wistar rats }\end{array}$ & $\begin{array}{l}\text { EPM, } \\
\text { MWM, } \\
\text { LAT }\end{array}$ & & $\begin{array}{l}\text { (Kaur and } \\
\text { Mehan, } \\
\text { 2015) }\end{array}$ \\
\hline
\end{tabular}




\begin{tabular}{|c|c|c|c|c|c|c|}
\hline Compounds & $\begin{array}{l}\text { Plant/dietary } \\
\text { sources }\end{array}$ & Test doses & Animal models & $\begin{array}{l}\text { Behavioral } \\
\text { tests }\end{array}$ & Actions & Ref \\
\hline Erucic acid & Raphanus sativus & $\begin{array}{l}1 ; 3 ; 10 \mathrm{mg} / \\
\mathrm{kg} / \text { day }\end{array}$ & $\begin{array}{l}\text { Scopolamine }(1 \mathrm{mg} / \mathrm{kg} / \text { day }) \\
\text { induced } \mathrm{CI} \text { in male mice }\end{array}$ & $\begin{array}{l}\text { PAT, YM, } \\
\text { MWM }\end{array}$ & $\begin{array}{l}\text { Erucic acid enhanced memory performance by } \\
\text { increasing PI3K, PKC, ERK, CREB, and AKT } \\
\text { phosphorylation levels. }\end{array}$ & $\begin{array}{l}\text { (Kim et al., } \\
\text { 2016a) }\end{array}$ \\
\hline Ferulic acid & Allium tuberosum & $\begin{array}{l}0.002 \% \\
0.005 \%(w / v)\end{array}$ & $\begin{array}{l}\text { TMT }(2.5 \mathrm{mg} / \mathrm{kg} / \text { day }) \text { induced } \\
\text { cognitive deficit in male mice }\end{array}$ & PAT, YM & $\begin{array}{l}\text { Ferulic acid prevented cognitive dysfunction by } \\
\text { activating ChAT activity in the brain. }\end{array}$ & $\begin{array}{l}\text { (Kim et al., } \\
\text { 2007b) }\end{array}$ \\
\hline Forsythiaside & $\begin{array}{l}\text { Forsythia } \\
\text { suspense }\end{array}$ & $\begin{array}{l}2,5 ; 5 ; 10 ; 20 \\
\mathrm{mg} / \mathrm{kg} / \text { day }\end{array}$ & $\begin{array}{l}\text { Scopolamine }(1 \mathrm{mg} / \mathrm{kg} / \text { day }) \\
\text { induced memory impairment } \\
\text { in male mice }\end{array}$ & PAT, MWM & $\begin{array}{l}\text { Forsythiaside enhanced learning and memory } \\
\text { performance by protecting the brain from lipid } \\
\text { peroxidation. }\end{array}$ & $\begin{array}{l}\text { (Kim et al., } \\
\text { 2009a) }\end{array}$ \\
\hline Genistein & $\begin{array}{l}\text { Glycine } \max \\
\text { (soybean) }\end{array}$ & $\begin{array}{l}10 ; 20 ; 40 \mathrm{mg} / \\
\mathrm{kg} / \text { day }\end{array}$ & $\begin{array}{l}\text { Scopolamine }(0.75 \mathrm{mg} / \mathrm{kg} / \mathrm{day}) \\
\text { induced amnesia in male mice }\end{array}$ & $\begin{array}{l}\text { OFT, } \\
\text { OLRT, } \\
\text { MWM }\end{array}$ & $\begin{array}{l}\text { Genistein enhanced memory by promoting cholinergic } \\
\text { neurotransmission (decreasing AChE activity and } \\
\text { increasing ChAT activity and ACh levels) and by } \\
\text { enhancing antioxidative capacity (increasing SOD } \\
\text { activity and GSH content and decreasing MDA levels). It } \\
\text { also induced the ERK/CREB/BDNF signaling pathway } \\
\text { in the hippocampus. }\end{array}$ & $\begin{array}{l}\text { (Lu et al., } \\
\text { 2018) }\end{array}$ \\
\hline $\begin{array}{l}\text { Ginsenoside Rg5 } \\
\text { Ginsenoside Rh3 }\end{array}$ & Panax ginseng & $\begin{array}{l}5 ; 10 ; 20 \mathrm{mg} / \\
\mathrm{kg} / \text { day }\end{array}$ & $\begin{array}{l}\text { Scopolamine }(1 \mathrm{mg} / \mathrm{kg} / \text { day }) \\
\text { induced memory deficit in } \\
\text { male mice }\end{array}$ & $\begin{array}{l}\text { PAT, YM, } \\
\text { MWM }\end{array}$ & $\begin{array}{l}\text { Ginsenoside Rg5 and Rh3 inhibited AChE activity and } \\
\text { increased CREB activation and BDNF expression, to } \\
\text { improve memory impairment. }\end{array}$ & (Kim et al., \\
\hline \multirow[t]{4}{*}{ Gintonin } & & $\begin{array}{l}25 ; 50 ; 100 \\
\mathrm{mg} / \mathrm{kg} / \text { day }\end{array}$ & $\begin{array}{l}\text { Scopolamine }(0.5 \mathrm{mg} / \mathrm{kg} / \text { day }) \\
\text { induced memory impairment } \\
\text { in male C57BL } 6 \text { mice }\end{array}$ & PAT, MWM & \multirow{3}{*}{$\begin{array}{l}\text { Gintonin reversed memory and cholinergic impairments } \\
\text { by acting as lysophosphatidic acid (LPA) receptor } \\
\text { ligand to increase ACh release and ChAT expression in } \\
\text { hippocampus. }\end{array}$} & \multirow[t]{3}{*}{$\begin{array}{l}\text { (Kim et al., } \\
\text { 2015) }\end{array}$} \\
\hline & & $\begin{array}{l}25 ; 50 \mathrm{mg} / \mathrm{kg} / \\
\text { day }\end{array}$ & $\begin{array}{l}\text { Amyloid- } \beta \text { protein }(400 \\
\text { pmol) induced cholinergic } \\
\text { dysfunction in male } \mathrm{C} 57 \mathrm{BL} / 6\end{array}$ & & & \\
\hline & & & $\begin{array}{l}\text { Male APP and PSEN-1 } \\
\text { transgenic mice as an AD } \\
\text { model }\end{array}$ & & & \\
\hline & & $50 \mathrm{mg} / \mathrm{kg} /$ day & $\begin{array}{l}\text { Normal (not treated) male } \\
\text { mice }\end{array}$ & CFCT & $\begin{array}{l}\text { Gintonin enhanced memory by increasing pCREB and } \\
\text { BDNF expression. }\end{array}$ & $\begin{array}{l}\text { (Kim et al., } \\
\text { 2016b) }\end{array}$ \\
\hline Gluco-obtusifolin & Cassia obtusifolia & $\begin{array}{l}0.5 ; 1 ; 2 ; 4 \mathrm{mg} / \\
\mathrm{kg} / \text { day }\end{array}$ & $\begin{array}{l}\text { Scopolamine }(1 \mathrm{mg} / \mathrm{kg} / \text { day }) \\
\text { induced memory impairment } \\
\text { in male mice }\end{array}$ & PAT, MWM & $\begin{array}{l}\text { Gluco-obtusifolin reversed memory impairment by } \\
\text { acting as an AChE inhibitor. }\end{array}$ & $\begin{array}{l}\text { (Dong et al., } \\
2009 \text { b) }\end{array}$ \\
\hline Gomisin A & $\begin{array}{l}\text { Schizandra } \\
\text { chinesis }\end{array}$ & $\begin{array}{l}2.5 ; 5 ; 10 ; 20 \\
\mathrm{mg} / \mathrm{kg} / \text { day }\end{array}$ & $\begin{array}{l}\text { Scopolamine }(1 \mathrm{mg} / \mathrm{kg} / \text { day }) \\
\text { induced memory impairment } \\
\text { in male mice }\end{array}$ & $\begin{array}{l}\text { PAT, YM, } \\
\text { MWM }\end{array}$ & $\begin{array}{l}\text { Gomisin A improved spatial long-term and short-term } \\
\text { memory by inhibiting AChE activity. }\end{array}$ & $\begin{array}{l}\text { (Kim et al., } \\
\text { 2006) }\end{array}$ \\
\hline Gypenoside TN-2 & $\begin{array}{l}\text { Gynostemma } \\
\text { pentaphyllum }\end{array}$ & $\begin{array}{l}10 ; 20 ; 40 \mathrm{mg} / \\
\mathrm{kg} / \text { day }\end{array}$ & $\begin{array}{l}\text { Scopolamine }(0.9 \mathrm{mg} / \mathrm{kg} / \text { day }) \\
\text { induced learning deficit in } \\
\text { male mice }\end{array}$ & $\begin{array}{l}\text { PAT, YM, } \\
\text { MWM }\end{array}$ & $\begin{array}{l}\text { Gypenoside TN-2 inhibited memory and learning } \\
\text { impairment by activating the CREB/BDNF signaling } \\
\text { pathways. }\end{array}$ & $\begin{array}{l}\text { (Hong et al., } \\
\text { 2011) }\end{array}$ \\
\hline Harmine & Peganum harmala & $20 \mathrm{mg} / \mathrm{kg} /$ day & $\begin{array}{l}\text { Scopolamine }(1 \mathrm{mg} / \mathrm{kg} / \text { day }) \\
\text { induced memory impairment } \\
\text { in male C57BL } / 6 \text { mice and } \\
\text { male APP } / \mathrm{PS} 1 \text { transgenic mice }\end{array}$ & MWM & $\begin{array}{l}\text { Harmine enhanced spatial cognition and reversed } \\
\text { memory impairment by inhibiting AChE activity and } \\
\text { inducing Egr-1, c-Fos, and c-Jun expression. }\end{array}$ & $\begin{array}{l}\text { (He et al., } \\
2015)\end{array}$ \\
\hline Huperzine A & Huperzia serrata & $0.14 \mathrm{mg} / \mathrm{kg} /$ day & $\begin{array}{l}\text { Scopolamine }(1.5 \mathrm{mg} / \mathrm{kg} / \\
\text { day) induced amnesia in male } \\
\text { Sprague Dawley rats }\end{array}$ & MWM & $\begin{array}{l}\text { Huperzine A enhanced spatial learning and memory } \\
\text { ability by inhibiting AChE activity and modulating } \\
\text { oxidative stress damage (increasing SOD and GSH- } \\
\text { Px activities and decreasing MDA levels) in the } \\
\text { hippocampus and cerebral cortex. }\end{array}$ & $\begin{array}{l}\text { (Shi et al., } \\
\text { 2010) }\end{array}$ \\
\hline Imperatorin & $\begin{array}{l}\text { Angelica dahurica } \\
\text { Angelica } \\
\text { archangelica }\end{array}$ & $\begin{array}{l}1 ; 5 ; 10 \mathrm{mg} / \\
\mathrm{kg} / \text { day }\end{array}$ & $\begin{array}{l}\text { Scopolamine }(1 \mathrm{mg} / \mathrm{kg} / \mathrm{day}) \\
\text { induced CI and oxidative stress } \\
\text { in naive male Swiss mice }\end{array}$ & PAT, LAT & $\begin{array}{l}\text { Imperatorin improved memory performance by } \\
\text { increasing enzymatic antioxidant (SOD and GSH-Px) } \\
\text { activity and decreasing lipid peroxidation (MDA) levels } \\
\text { in the cortex and hippocampus. }\end{array}$ & $\begin{array}{l}\text { (Budzynska } \\
\text { et al., 2015) }\end{array}$ \\
\hline Kolaviron & Garcinia kola & $\begin{array}{l}25 ; 50 ; 100 \\
\mathrm{mg} / \mathrm{kg} / \mathrm{day}\end{array}$ & $\begin{array}{l}\text { Scopolamine }(3 \mathrm{mg} / \mathrm{kg}) \\
\text { induced memory impairment } \\
\text { in male Albino rats }\end{array}$ & YM, MWM & $\begin{array}{l}\text { Kolaviron improved short- and long-term memory by } \\
\text { inhibiting AChE, decreasing oxidative stress (reducing } \\
\text { nitrite and MDA levels), and increasing antioxidant } \\
\text { capacity (increasing GSH-Px and SOD levels) in the } \\
\text { hippocampus, stratum, and prefrontal cortex. }\end{array}$ & $\begin{array}{l}\text { (Ishola et al., } \\
\text { 2017) }\end{array}$ \\
\hline Lancemaside A & C. lanceolata & $\begin{array}{l}10 ; 20 \mathrm{mg} / \mathrm{kg} / \\
\text { day }\end{array}$ & $\begin{array}{l}\text { Scopolamine }(1 \mathrm{mg} / \mathrm{kg} / \text { day }) \\
\text { induced memory impairment } \\
\text { in male mice }\end{array}$ & $\begin{array}{l}\text { PAT, YM, } \\
\text { MWM }\end{array}$ & $\begin{array}{l}\text { Lancemaside A reversed memory and learning } \\
\text { impairment condition via AChE activity inhibition and } \\
\text { CREB/BDNF signaling pathway modulation. }\end{array}$ & $\begin{array}{l}\text { (Jung et al., } \\
\text { 2012) }\end{array}$ \\
\hline $\begin{array}{l}\text { Ligustrazine } \\
\text { Phosphate }\end{array}$ & $\begin{array}{l}\text { Ligusticum } \\
\text { chuanxiong }\end{array}$ & $110 \mathrm{mg} / \mathrm{kg} /$ day & $\begin{array}{l}\text { Scopolamine }(1.5 \mathrm{mg} / \mathrm{kg} / \\
\text { day) induced amnesia in male } \\
\text { Sprague Dawley rats }\end{array}$ & MWM & $\begin{array}{l}\text { Ligustrazine phosphate enhanced spatial learning } \\
\text { and memory ability by inhibiting AChE activity and } \\
\text { modulating oxidative stress damage (increased SOD and } \\
\text { GSH-Px activities and decreased MDA levels) in the } \\
\text { hippocampus and cerebral cortex. }\end{array}$ & $\begin{array}{l}\text { (Shi et al., } \\
\text { 2010) }\end{array}$ \\
\hline Loganin & $\begin{array}{l}\text { Flos lonicerae } \\
\text { Fruit cornus } \\
\text { Strychonos nux } \\
\text { vomica }\end{array}$ & $\begin{array}{l}20 ; 40 \mathrm{mg} / \mathrm{kg} / \\
\text { day }\end{array}$ & $\begin{array}{l}\text { Scopolamine }(0.5 \mathrm{mg} / \mathrm{kg} / \text { day }) \\
\text { induced memory impairment }\end{array}$ & $\begin{array}{l}\text { YM, PAT, } \\
\text { MWM }\end{array}$ & $\begin{array}{l}\text { Loganin reversed memory impairment by inhibiting } \\
\text { AChE activity in the hippocampus and frontal cortex. }\end{array}$ & $\begin{array}{l}\text { (Kwon } \\
\text { et al., 2009) }\end{array}$ \\
\hline
\end{tabular}




\begin{tabular}{|c|c|c|c|c|c|c|}
\hline Compounds & $\begin{array}{l}\text { Plant/dietary } \\
\text { sources }\end{array}$ & Test doses & Animal models & $\begin{array}{l}\text { Behavioral } \\
\text { tests }\end{array}$ & Actions & Ref \\
\hline Luteolin & $\begin{array}{l}\text { Chrysanthemum } \\
\text { morifolium }\end{array}$ & $\begin{array}{l}10 ; 20 \mathrm{mg} / \mathrm{kg} / \\
\text { day }\end{array}$ & $\begin{array}{l}\text { Streptozotocin ( } 3 \mathrm{mg} / \mathrm{kg} / \text { day }) \\
\text { induced AD in male Wistar } \\
\text { rats }\end{array}$ & MWM & $\begin{array}{l}\text { Luteolin improved spatial learning and memory; it also } \\
\text { increased the thickness of the CA1 pyramidal layer } \\
\text { structure. The exact mode of action is not known, but it } \\
\text { might be associated with its antioxidative effect. }\end{array}$ & $\begin{array}{l}\text { (Wang et al., } \\
\text { 2016) }\end{array}$ \\
\hline Mangiferin & $\begin{array}{l}\text { Annemarrhena } \\
\text { asphodeloides }\end{array}$ & $\begin{array}{l}10 ; 20 \mathrm{mg} / \mathrm{kg} / \\
\text { day }\end{array}$ & $\begin{array}{l}\text { Scopolamine }(1 \mathrm{mg} / \mathrm{kg} / \text { day }) \\
\text { induced learning deficit in } \\
\text { male mice }\end{array}$ & $\begin{array}{l}\text { PAT, } \\
\text { MWM }\end{array}$ & $\begin{array}{l}\text { Mangiferin improved long-term cholinergic memory by } \\
\text { inhibiting AChE activity and proinflammatory cytokines } \\
\left(\mathrm{TNF} \alpha \text { and } \mathrm{NF}_{\mathrm{K}} \mathrm{B} \text { ) in BV-2 microglial cells. }\right.\end{array}$ & $\begin{array}{l}\text { (Jung et al., } \\
\text { 2009) }\end{array}$ \\
\hline Myricetin & $\begin{array}{l}\text { Berries, } \\
\text { vegetables }\end{array}$ & $\begin{array}{l}25 ; 50 \mathrm{mg} / \mathrm{kg} / \\
\text { day }\end{array}$ & $\begin{array}{l}\text { Scopolamine }(0.2 \mathrm{mg} / \mathrm{kg} / \text { day }) \\
\text { supplemented with a high iron } \\
\text { dose }(75 \mathrm{mg} / \mathrm{kg} / \text { day }) \text { induced } \\
\text { memory impairment in male } \\
\text { mice }\end{array}$ & MWM & $\begin{array}{l}\text { Myricetin increased spatial learning and memory } \\
\text { via AChE activity inhibition and brain iron level } \\
\text { downregulation. It also protected the brain from } \\
\text { oxidative damage. }\end{array}$ & $\begin{array}{l}\text { (Wang et al., } \\
\text { 2017) }\end{array}$ \\
\hline Nodakenin & Angelica gigas & $\begin{array}{l}2.5 ; 5 ; 10 ; 20 \\
\mathrm{mg} / \mathrm{kg} / \mathrm{day}\end{array}$ & $\begin{array}{l}\text { Scopolamine }(1 \mathrm{mg} / \mathrm{kg} / \text { day }) \\
\text { induced memory disruption in } \\
\text { male mice }\end{array}$ & $\begin{array}{l}\text { PAT, YM, } \\
\text { MWM }\end{array}$ & $\begin{array}{l}\text { Nodakenin ameliorated spatial long-term and working } \\
\text { memory dysfunction by inhibiting AChE activity in the } \\
\text { cholinergic signaling pathway. }\end{array}$ & $\begin{array}{l}\text { (Kim et al., } \\
2007 \mathrm{c})\end{array}$ \\
\hline Obtusifolin & C. obtusifolia & $\begin{array}{l}0.25 ; 0.5 ; 1 ; 2 \\
\mathrm{mg} / \mathrm{kg} / \mathrm{day}\end{array}$ & $\begin{array}{l}\text { Scopolamine }(1 \mathrm{mg} / \mathrm{kg} / \text { day }) \\
\text { induced memory impairment } \\
\text { in male mice }\end{array}$ & $\begin{array}{l}\text { PAT, } \\
\text { MWM }\end{array}$ & $\begin{array}{l}\text { Obtusifolin reversed memory impairment by acting as } \\
\text { an AChE inhibitor. }\end{array}$ & $\begin{array}{l}\text { (Kim et al., } \\
\text { 2009b) }\end{array}$ \\
\hline Oroxylin A & $\begin{array}{l}\text { Scutellaria } \\
\text { baicalensis }\end{array}$ & $\begin{array}{l}2.5 ; 5 ; 10 ; 20 \\
\mathrm{mg} / \mathrm{kg} / \mathrm{day}\end{array}$ & $\begin{array}{l}\text { Scopolamine }(1 \mathrm{mg} / \mathrm{kg}) \text { or } \\
\text { diazepam }(1 \mathrm{mg} / \mathrm{kg}) \text { induced } \\
\text { memory impairment in male } \\
\text { mice }\end{array}$ & $\begin{array}{l}\text { PAT, YM, } \\
\text { MWM }\end{array}$ & $\begin{array}{l}\text { Oroxylin A improved CI by acting as a } \mathrm{GABA}_{\mathrm{A}} \text { receptor } \\
\text { antagonist. }\end{array}$ & $\begin{array}{l}\text { (Kim et al., } \\
\text { 2007d) }\end{array}$ \\
\hline Paeoniflorin & Paeonia lactiflora & $40 \mathrm{mg} / \mathrm{kg} /$ day & $\begin{array}{l}\text { Vascular dementia in male } \\
\text { Sprague Dawley rats }\end{array}$ & MWM & $\begin{array}{l}\text { Paeoniflorin reversed memory impairment and inhibited } \\
\text { and reduced cerebral hypoperfusion and hippocampal } \\
\text { morphological-ultrastructural changes by decreasing } \\
\text { proinflammatory cytokine expression (IL-1 } \beta \text {, IL-6, } \\
\text { TNF- } \alpha \text {, and NO) via mTOR/NF- } \mathrm{B} \text { signaling pathway } \\
\text { inhibition, increasing anti-inflammatory cytokines } \\
\text { (IL-10, TGF- } \beta 1 \text { ) via PI3K/AKT signaling pathway } \\
\text { activation, and also activating cannabinoid receptor } 2 \text { in } \\
\text { the hippocampus. }\end{array}$ & $\begin{array}{l}\text { (Ohta et al., } \\
\text { 1993) }\end{array}$ \\
\hline Palmatine & Coptidis rhizoma & $\begin{array}{l}0,1 ; 0,5 ; 1 \mathrm{mg} / \\
\mathrm{kg} / \text { day }\end{array}$ & $\begin{array}{l}\text { Scopolamine }(0.4 \mathrm{mg} / \mathrm{kg}) \text { and } \\
\text { diazepam }(1 \mathrm{mg} / \mathrm{kg}) \text { induced } \\
\text { amnesia in Swiss-Albino male } \\
\text { mice }\end{array}$ & $\begin{array}{l}\text { EPM, } \\
\text { MWM }\end{array}$ & $\begin{array}{l}\text { Palmatine enhanced memory by acting as an AChE } \\
\text { inhibitor and interacted with the GABA-benzodiazepine } \\
\text { pathway. It also acted as an antioxidative agent. }\end{array}$ & $\begin{array}{l}\text { (Dhingra } \\
\text { and Kumar, } \\
\text { 2012) }\end{array}$ \\
\hline Phytoceramide & $\begin{array}{l}\text { Sweet potatoes, } \\
\text { rice bran, and } \\
\text { wheat }\end{array}$ & $\begin{array}{l}5 ; 10 ; 20 ; 50 \\
\mathrm{mg} / \mathrm{kg} / \text { day }\end{array}$ & $\begin{array}{l}\text { Scopolamine }(1 \mathrm{mg} / \mathrm{kg} / \text { day }) \\
\text { induced memory deficit in } \\
\text { male mice }\end{array}$ & PAT, YM & $\begin{array}{l}\text { Phytoceramide increased cognitive performance and } \\
\text { neurogenesis in the hippocampal dentate gyrus regions } \\
\text { via CREB/BDNF signaling pathway activation. }\end{array}$ & $\begin{array}{l}\text { (Lee et al., } \\
\text { 2013) }\end{array}$ \\
\hline Polygalacic acid & P. tenuifolia & $\begin{array}{l}3 ; 6 ; 12 \mathrm{mg} / \\
\mathrm{kg} / \text { day }\end{array}$ & $\begin{array}{l}\text { Scopolamine }(1 \mathrm{mg} / \mathrm{kg} / \text { day }) \\
\text { induced memory deficit in } \\
\text { male mice }\end{array}$ & MWM & $\begin{array}{l}\text { Polygalacic acid reversed CI by modulating cholinergic } \\
\text { systems (decreased AChE activity, increased ChAT } \\
\text { activity, and ACh levels) in the hippocampus and } \\
\text { frontal cortex. It also showed anti-inflammatory activity } \\
\text { (attenuated IL- } \beta \text { and enhanced IL-10) and demonstrated } \\
\text { antioxidative effects (increased SOD activity, decreased } \\
\text { MDA, and GSH levels) in the brain. }\end{array}$ & $\begin{array}{l}\text { (Guo et al., } \\
\text { 2016) }\end{array}$ \\
\hline $\begin{array}{l}\text { Pseudoginsenoside- } \\
\text { F }_{11}\end{array}$ & $\begin{array}{l}\text { Panax } \\
\text { quinquefolium }\end{array}$ & $\begin{array}{l}1.6 ; 8 \mathrm{mg} / \mathrm{kg} / \\
\text { day }\end{array}$ & $\begin{array}{l}\mathrm{A} \beta_{1-42}(410 \mathrm{pmol}) \text { induced } \mathrm{AD} \\
\text { in male mice and not treated } \\
\mathrm{APP} / \mathrm{PS} 1 \text { mice }\end{array}$ & $\begin{array}{l}\text { MWM, } \\
\text { PAT }\end{array}$ & $\begin{array}{l}\text { Pseudoginsenoside- } F_{11} \text { improved behavioral } \\
\text { performance and inhibited APP as well as A } \beta_{1-42} \\
\text { production via oxidative stress modulation (increased } \\
\text { SOD and GSH-Px activities and decreased MDA levels). } \\
\text { It also interfered with apoptosis pathways (decreased } \\
\text { JNK2, p53, and cleaved caspase } 3 \text { expression) in the } \\
\text { cortex and hippocampus. }\end{array}$ & $\begin{array}{l}\text { (Wang et al., } \\
\text { 2013) }\end{array}$ \\
\hline Quercetine & $\begin{array}{l}\text { Vegetables, } \\
\text { fruits, e.g., } \\
\text { onions, potatoes, } \\
\text { cabbages, } \\
\text { lettuces, apples, } \\
\text { mangoes, and } \\
\text { black currants }\end{array}$ & $\begin{array}{l}50 ; 75 ; 100 \\
\mathrm{mg} / \mathrm{kg} / \text { day }\end{array}$ & $\begin{array}{l}\mathrm{D} \text {-galactose }(50 \mathrm{mg} / \mathrm{kg} / \text { day }) \\
\text { induced memory impairment- } \\
\text { aging model in male mice }\end{array}$ & MWM & $\begin{array}{l}\text { Quercetine improved exploratory behavior, spatial } \\
\text { learning, and memory via oxidative stress prevention } \\
\text { (decreased *OH levels and increased GSH content) in } \\
\text { the hippocampus and cerebral cortex. }\end{array}$ & $\begin{array}{l}\text { (Liu et al., } \\
\text { 2006) }\end{array}$ \\
\hline \multirow[t]{2}{*}{ Resveratrol } & \multirow[t]{2}{*}{ Grapes } & $\begin{array}{l}12.5 ; 25 ; 50 \\
\mathrm{mg} / \mathrm{kg} / \text { day }\end{array}$ & $\begin{array}{l}\text { Scopolamine }(0.6 \mathrm{mg} / \mathrm{kg} / \\
\text { day }) \text { and mecamylamine }(10 \\
\mathrm{mg} / \mathrm{kg} / \text { day }) \text { induced memory } \\
\text { impairment in male Wistar rats }\end{array}$ & $\begin{array}{l}\text { PAT, } \\
\text { MWM, } \\
\text { LAT }\end{array}$ & $\begin{array}{l}\text { Resveratrol improved learning and memory performance } \\
\text { in scopolamine-induced rats but not in mecamylamine- } \\
\text { induced rats. The mode of action might target the } \\
\text { muscarinic system rather than the nicotinic system. }\end{array}$ & $\begin{array}{l}\text { (Gacar } \\
\text { et al., 2011) }\end{array}$ \\
\hline & & $\begin{array}{l}10 ; 20 ; 40 \mathrm{mg} / \\
\mathrm{kg} / \text { day }\end{array}$ & $\begin{array}{l}\mathrm{A} \beta_{1-42}(0.4 \mu \mathrm{g} / \text { side } \mathrm{CA} 1) \\
\text { induced memory impairment } \\
\text { in male mice }\end{array}$ & $\begin{array}{l}\text { MWM, } \\
\text { PAT }\end{array}$ & $\begin{array}{l}\text { Resveratrol ameliorated learning and memory } \\
\text { impairment by activating PDE4-related signaling } \\
\text { (decreased PDE4 expression and upregulated pCREB } \\
\text { and BDNF expression), decreasing proinflammatory } \\
\text { cytokines (IL- } 6 \text { and Il- } \beta \text { ), and regulating apoptotic } \\
\text { proteins expression (increased Bcl } 2 \text { and decreased Bax) } \\
\text { in the hippocampus. }\end{array}$ & $\begin{array}{l}\text { (Wang et al., } \\
\text { 2016) }\end{array}$ \\
\hline
\end{tabular}




\begin{tabular}{|c|c|c|c|c|c|c|}
\hline Compounds & $\begin{array}{l}\text { Plant/dietary } \\
\text { sources }\end{array}$ & Test doses & Animal models & $\begin{array}{l}\text { Behavioral } \\
\text { tests }\end{array}$ & Actions & Ref \\
\hline Rosmarinic acid & Boraginaceae & $\begin{array}{l}1 ; 2 ; 4 ; 8 \mathrm{mg} / \\
\mathrm{kg} / \text { day }\end{array}$ & $\begin{array}{l}\text { Normal (not treated) male } \\
\text { mice }\end{array}$ & MWM & $\begin{array}{l}\text { Rosmarinic acid enhanced spatial long-term memory by } \\
\text { inhibiting POP activity. }\end{array}$ & $\begin{array}{l}\text { (Park et al., } \\
\text { 2010) }\end{array}$ \\
\hline Schisandrin B & $\begin{array}{l}\text { Schisandra } \\
\text { chinensis }\end{array}$ & $\begin{array}{l}10 ; 25 ; 50 \mathrm{mg} / \\
\mathrm{kg} / \text { day }\end{array}$ & $\begin{array}{l}\text { Scopolamine }(1 \mathrm{mg} / \mathrm{kg}) \\
\text { induced memory deficit in } \\
\text { male Balb-c mice }\end{array}$ & $\begin{array}{l}\text { PAT, } \\
\text { MWM }\end{array}$ & $\begin{array}{l}\text { Schisandrin B prevented learning and memory } \\
\text { impairment via AChE inhibition and antioxidant status } \\
\text { regulation (decreased nitrite and MDA levels and } \\
\text { increased GSH, GSH-Px, and SOD levels) in the brain. }\end{array}$ & $\begin{array}{l}\text { (Giridharan } \\
\text { et al., 2011) }\end{array}$ \\
\hline Stevioside & Stevia rebaudiana & $250 \mathrm{mg} / \mathrm{kg} /$ day & $\begin{array}{l}\text { Scopolamine }(0.5 \mathrm{mg} / \mathrm{kg} / \mathrm{day}) \\
\text { induced memory impairment } \\
\text { in Wistar rats }\end{array}$ & MWM & $\begin{array}{l}\text { Stevioside improved learning and memory performance } \\
\text { by inhibiting AChE activity and acted as an antioxidant } \\
\text { (decreased TBARS level and increased GSH content) } \\
\text { in the brain. }\end{array}$ & $\begin{array}{l}\text { (Sharma } \\
\text { et al., 2010) }\end{array}$ \\
\hline Stigmasterol & $\begin{array}{l}\text { Soybean, Calabar } \\
\text { bean, and } \\
\text { rapeseed }\end{array}$ & $\begin{array}{l}2.5 ; 5 ; 10 ; 20 \\
\mathrm{mg} / \mathrm{kg} / \text { day }\end{array}$ & $\begin{array}{l}\text { Scopolamine }(1 \mathrm{mg} / \mathrm{kg} / \mathrm{day}) \\
\text { induced memory impairment } \\
\text { in male mice }\end{array}$ & $\begin{array}{l}\text { PAT, } \\
\text { MWM }\end{array}$ & $\begin{array}{l}\text { Stigmasterol counteracted memory impairment by } \\
\text { increasing pERK and pCREB expression levels in the } \\
\text { hippocampus. }\end{array}$ & $\begin{array}{l}\text { (Park et al., } \\
\text { 2012) }\end{array}$ \\
\hline Sulforaphane & $\begin{array}{l}\text { Cruciferous } \\
\text { vegetables e.g., } \\
\text { broccoli, cabbage, } \\
\text { watercress, and } \\
\text { Brussels sprouts }\end{array}$ & $\begin{array}{l}10 ; 50 \mathrm{mg} / \mathrm{kg} / \\
\text { day }\end{array}$ & $\begin{array}{l}\text { Scopolamine }(1 \mathrm{mg} / \mathrm{kg} / \text { day }) \\
\text { induced memory impairment } \\
\text { in female C57BL } / 6 \text { mice }\end{array}$ & MWM & $\begin{array}{l}\text { Sulforaphane improved memory and learning ability via } \\
\text { cholinergic system modulation (increased ACh level and } \\
\text { ChAT expression and decreased AChE activity) in the } \\
\text { hippocampus and frontal cortex. }\end{array}$ & $\begin{array}{l}\text { (Lee et al., } \\
\text { 2014) }\end{array}$ \\
\hline Tanshinone I & S. miltiorrhiza & $\begin{array}{l}0.5 ; 1 ; 2 ; 4 \mathrm{mg} / \\
\mathrm{kg} / \text { day }\end{array}$ & $\begin{array}{l}\text { Scopolamine }(1 \mathrm{mg} / \mathrm{kg} / \text { day }) \\
\text { induced memory impairment }\end{array}$ & PAT & $\begin{array}{l}\text { Tanshinone I and II A ameliorated memory and learning } \\
\text { abnormalities by inhibiting AChE activity. }\end{array}$ & $\begin{array}{l}\text { (Kim et al., } \\
\text { 2007e) }\end{array}$ \\
\hline Tanshinone II A & & $\begin{array}{l}2.5 ; 5 ; 10 ; 20 \\
\mathrm{mg} / \mathrm{kg} / \text { day }\end{array}$ & in male mice & & & \\
\hline \multirow[t]{3}{*}{ Thymoquinone } & Nigella sativa & $\begin{array}{l}2.5 ; 5 ; 10 \mathrm{mg} / \\
\mathrm{kg} / \text { day }\end{array}$ & $\begin{array}{l}\text { D-galactose }(400 \mathrm{mg} / \mathrm{kg} / \text { day }) \\
\text { induced aging and memory } \\
\text { impairment in male Wistar rats }\end{array}$ & MWM & $\begin{array}{l}\text { Thymoquinone improved memory deficit by preventing } \\
\text { oxidative stress and neuroinflammation in the } \\
\text { hippocampus (increased GSH, reduced MDA level, } \\
\text { and reduced proteins level of TNF- } \alpha \text {, IL-1 } \beta \text {, AGEs, and } \\
\text { GFAP). }\end{array}$ & $\begin{array}{l}\text { (Oskouei } \\
\text { et al., 2020) }\end{array}$ \\
\hline & & $20 \mathrm{mg} / \mathrm{kg} /$ day & $\begin{array}{l}\mathrm{A} \beta_{1-42}(300 \text { pmol }) \text { induced AD } \\
\text { in female Sprague Dawley rats }\end{array}$ & MWM & $\begin{array}{l}\text { Thymoquinone enhanced spatial memory by acting as } \\
\text { anti-inflammatory (decreased IFN- } \gamma \text { ) and neurogenesis } \\
\text { inducer (increased DCX expression) in hippocampus. }\end{array}$ & $\begin{array}{l}\text { (Elibol } \\
\text { et al., 2019) }\end{array}$ \\
\hline & & & $\begin{array}{l}\text { Streptozotocin }(3 \mathrm{mg} / \mathrm{kg}) \\
\text { induced memory deficit in } \\
\text { female Sprague Dawley rats }\end{array}$ & $\begin{array}{l}\text { MWM, } \\
\text { PAT }\end{array}$ & $\begin{array}{l}\text { Thymoquinone increased regeneration of neuron through } \\
\text { MAPK pathways by activating JNK } 1 / 2 \text {, upregulating } \\
\text { mir124, and downregulating and ERK } 1 / 2 \text { and iNOS } \\
\text { enzyme in hippocampus. }\end{array}$ & $\begin{array}{l}\text { (Dalli et al., } \\
\text { 2018) }\end{array}$ \\
\hline $\begin{array}{l}\text { Trans- } \\
\text { cinnamaldehyde }\end{array}$ & $\begin{array}{l}\text { Cinnamomum } \\
\text { cassia }\end{array}$ & $\begin{array}{l}12.5 ; 25 ; 50 \\
\mathrm{mg} / \mathrm{kg} / \text { day }\end{array}$ & $\begin{array}{l}\text { Lipopolysaccharide }(0.33 \\
\mathrm{mg} / \mathrm{kg} / \mathrm{day}) \text { induced memory } \\
\text { impairment in male mice }\end{array}$ & $\begin{array}{l}\text { OFT, NOR, } \\
\text { MWM }\end{array}$ & $\begin{array}{l}\text { Trans-cinnamaldehyde alleviated memory deficit } \\
\text { and improved synaptic plasticity by reducing } \\
\text { neuroinflammation markers (iNOS and IL-1 } \beta \text { ) in the } \\
\text { microglia and inhibiting the MEK } 1 / 2 \text {-ERK } 1 / 2 \text { signaling } \\
\text { pathway in the hippocampus. }\end{array}$ & $\begin{array}{l}\text { (Zhang } \\
\text { et al., 2016) }\end{array}$ \\
\hline Vitexin & Vitex agnuscastus & $\begin{array}{l}25 ; 50 ; 100 \\
\mu \mathrm{M} \text { (i.c.v) }\end{array}$ & $\begin{array}{l}\text { Scopolamine }(10 \mu \mathrm{g} / \text { day i.c.v. }) \\
\text { induced memory impairment } \\
\text { in male Wistar rats }\end{array}$ & PAT & $\begin{array}{l}\text { Vitexin improved memory retrieval by directly } \\
\text { interacting with cholinergic and/or GABAergic } \\
\text { receptors. }\end{array}$ & $\begin{array}{l}\text { (Abbasi } \\
\text { et al., 2013) }\end{array}$ \\
\hline Zerumbone & Zingiber zerumbet & $\begin{array}{l}1 ; 10 \mathrm{mg} / \mathrm{kg} / \\
\text { day }\end{array}$ & $\begin{array}{l}\text { Scopolamine }(20 \mathrm{mg} / \mathrm{kg} / \text { day }) \\
\text { induced dementia and anxiety- } \\
\text { like behaviors in Sprague } \\
\text { Dawley rats }\end{array}$ & $\begin{array}{l}\text { OFT, EPM, } \\
\text { MWM }\end{array}$ & $\begin{array}{l}\text { Zerumbone reversed anxiety and depression-like } \\
\text { behaviors and inhibited memory impairment. The mode } \\
\text { of action is unknown but might be related to the GABA } A \\
\text { receptor. }\end{array}$ & $\begin{array}{l}\text { (Jafarian } \\
\text { et al., 2019) }\end{array}$ \\
\hline Z-Ligustilide & $\begin{array}{l}\text { A. gigas } \\
\text { L. chuanxiong }\end{array}$ & $\begin{array}{l}2.5 ; 10 ; 40 \mathrm{mg} / \\
\mathrm{kg} / \text { day }\end{array}$ & $\begin{array}{l}\text { Scopolamine }(2 \mathrm{mg} / \mathrm{kg} / \mathrm{day}) \\
\text { induced memory impairment } \\
\text { in SPF male mice }\end{array}$ & $\begin{array}{l}\text { MWM, } \\
\text { YM }\end{array}$ & $\begin{array}{l}\text { Z-Ligustilide enhanced spatial long-term and short- } \\
\text { term memory by stimulating the cholinergic system } \\
\text { (decreased AChE activity and increased ChAT activity). }\end{array}$ & $\begin{array}{l}\text { (Cheng } \\
\text { et al., 2011) }\end{array}$ \\
\hline
\end{tabular}

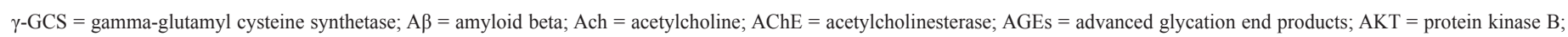

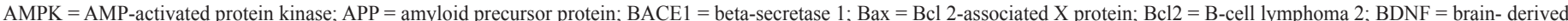

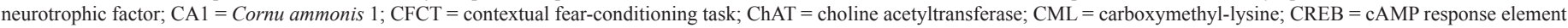

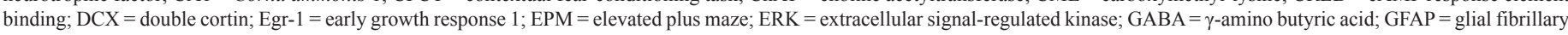

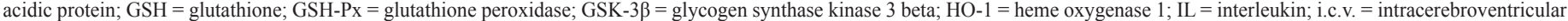

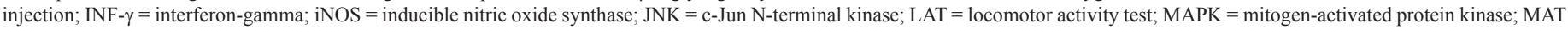

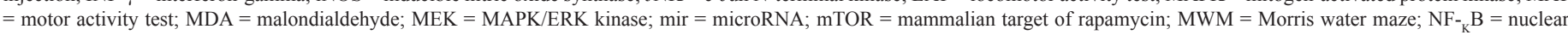

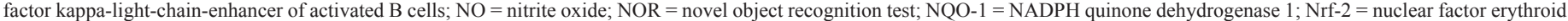

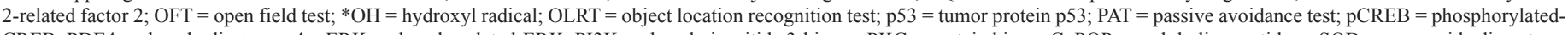

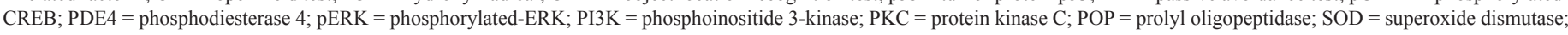
TBARS $=$ thiobarbituric acid-reactive substances; TGF $\beta=$ tumor growth factor beta; TNF $\alpha=$ tumor necrosis factor alpha; YM $=\mathrm{Y}$-maze; $\mathrm{ZM}=\mathrm{zero}$ maze.

drug design, especially for combating complex diseases, including neurodegenerative diseases (AD, Parkinson's disease, schizophrenia, and depression) and cancers. These diseases have multiple pathophysiological and pathological aspects manifested in their clinical symptoms. Therefore, a single target drug might be inadequate to effectively achieve the therapeutic goal (Ramsay et al., 2018). Consequently, an effective drug might be developed on the basis of multiple targets to cover complex therapeutic targets.

As a recent study indicated that CI is a complex disease involving genetic, environmental, and aging factors with 


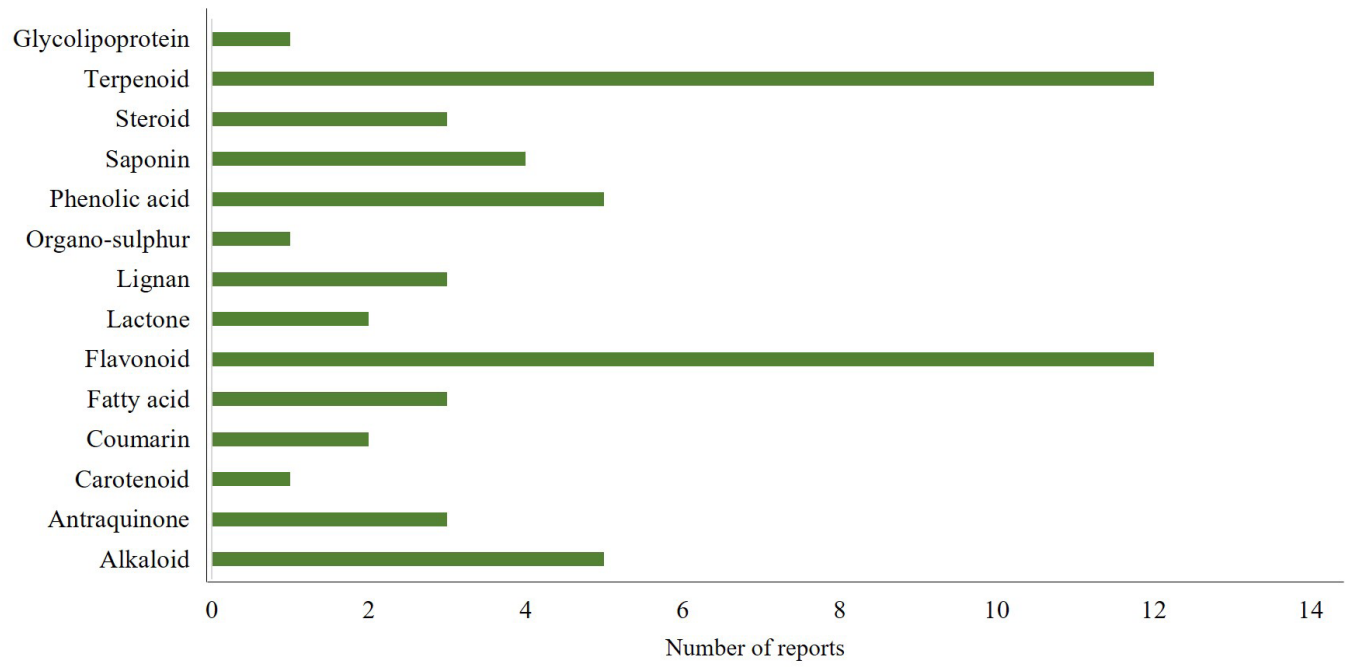

Figure 3. Chemical classes of compounds acting as memory enhancers in animal studies published from 2003 to 2020 . Among the group of compounds, flavonoid and terpenoid are the most frequently reported memory enhancers, whereas only little data are available for carotenoid and organosulfur compounds.

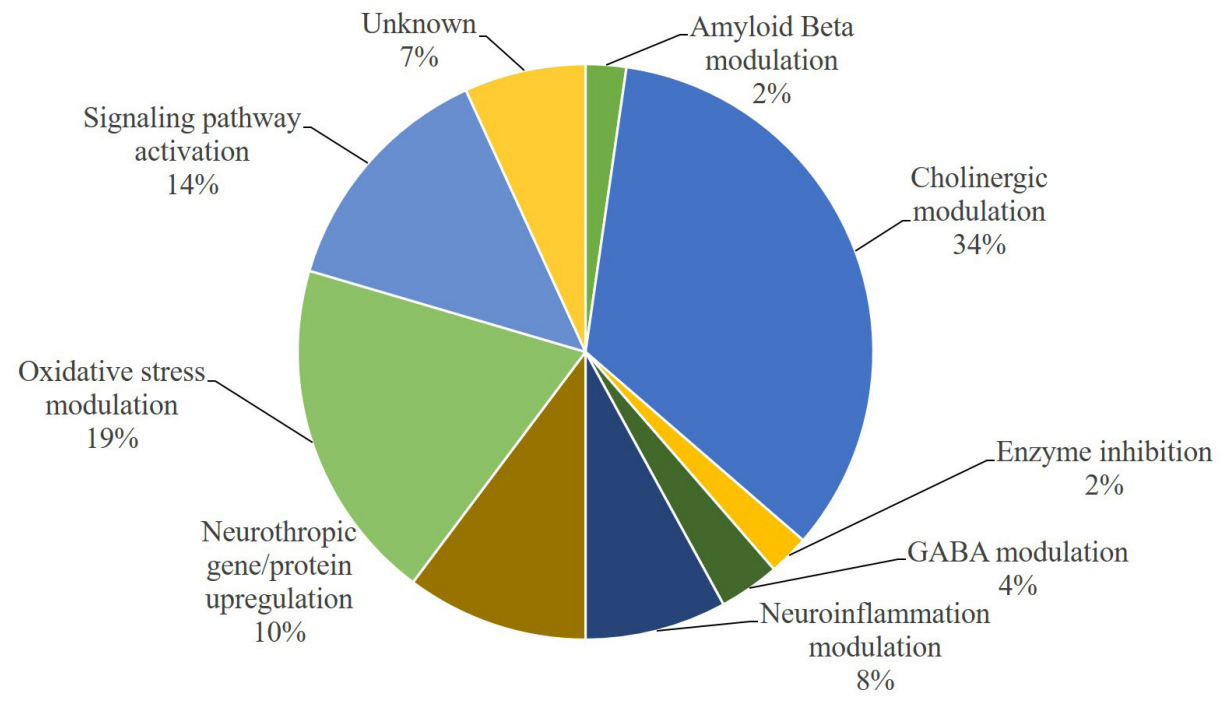

Figure 4. Comparison of the mechanism of action of plant natural products acting as cognitive enhancers evaluated in animal models. Modulation of cholinergic activity accounted for $34 \%$ of the mechanism, whereas oxidative stress modulation and signaling pathway activation accounted for $19 \%$ and $14 \%$, respectively. The other mechanism of actions was accounted less than $10 \%$.

complicated pathophysiology (Alber, 2017; Sun et al., 2017; Tiwari et al., 2019), a multitarget approach is needed for the development of CI drugs. In this regard, plant natural compounds represent a potential source. Plants serve compound diversity that is historically proven to inspire drug discovery and traditionally used for medicinal purposes in various diseases, including complex ones (Benek et al., 2020; Chen and Decker, 2013).

As previously shown in Table 1, many plant-derived natural compounds exhibited cognitive-enhancing activity in amnesic-animal models. Their potential effects were evaluated by behavioral testing, employing short and/or long-term spatial and working memory performance evaluations. Memory is an important factor in cognition function, and impairment of cognitive function is associated with the early stage of cognitive problems (Robertson, 2002). Based on Table 1, plant natural compounds were grouped on the basis of their mechanisms of action (Fig. 4). Figure 4 shows that the cholinergic nervous system is the major target of the majority of the potential natural compounds, followed by ROS/NOS and some of the signaling pathways in the CNS for their activity.

Fifteen compounds showed multitarget action, by at least three different mechanisms. These compounds were gintonin, thymoquinone, huperzine A, aloe emodin, curcumin, ellagic acid, genistein, kolaviron, resveratrol, stevioside, schisandrin B, sulforaphane, echinocystic acid, lancemaside A, and polygalacic acid, and they have a high potential to be further developed as 
drugs targeting CI. Polygalacic acid and genistein are the most potential and promising candidates as a new cognitive functionenhancing drug. These compounds can be found in Polygala tenuifolia and Glycine max (soybean). Polygalacic acid $(3 ; 6 ; 12$ $\mathrm{mg} / \mathrm{kg} ; \mathrm{p} . \mathrm{o})$ and genistein $(10 ; 20 ; 40 \mathrm{mg} / \mathrm{kg}$ and $10 ; 20 ; 40 \mathrm{mg} / \mathrm{kg}$; p.o) were able to inhibit memory impairment in mice induced by scopolamine. Polygalacic acid and genistein showed a synergistic effect in targeting CI. These compounds have several mechanisms (i.e., regulating the cholinergic nervous system, activating the extracellular signal-regulated kinase (ERK)/cAMP response element binding (CREB)/brain- derived neurotrophic factor (BDNF) signaling pathway, and protecting the hippocampus and frontal cortex from oxidative and inflammatory stresses). The activity of polygalacic acid and genistein is of note, as it protects the hippocampus and frontal cortex (the most important regions of CNS for cognition regulation) from injuries and stresses. However, further studies are required to clarify their antiamnesic activity in human using clinical trials (Guo et al., 2016; Lu et al., 2018).

\section{The limitations of natural cognitive enhancers from plants}

Plant natural compounds have a potential to be developed as a cognitive-enhancing agent. They provide a huge chemical diversity and might offer an alternative therapeutic approach. On the contrary, plant natural compounds have some limitations that restrict their development as a drug. Several clinical evidences indicated that herbal medicines and their metabolite constituents demonstrated inconsistent clinical outcomes. This due to the unclear pharmacokinetic aspect of the active compound, poor bioavailability, and lack of penetration across the blood-brain barrier. Consequently, these compounds failed to achieve the minimum therapeutic concentration in CNS, leading to the lack of efficacy. In addition, variability in the quality of plant raw material, harvesting process, extraction method, and production process also affect the quality of the final product (Kunle et al., 2012; Ratheesh et al., 2017).

\section{CONCLUSION}

Many studies showed that plant natural compounds have a positive influence on cognitive performance in animal experimental models. These compounds were able to improve cognitive functions and to enhance short/long-term spatial and working memories. Based on the current literature, we identified 15 plant natural compounds that showed multitarget action for combating CI. Polygalacic acid and genistein are among the most promising of these compounds, as they are able to interact with multiple molecular targets related to $\mathrm{CI}$ and are considered as promising lead compounds for drug development and dietary supplementation in the treatment of CI.

\section{ACKNOWLEDGMENTS}

The authors thank to the Ministry of Research, Technology and Higher Education (KEMENRISTEKDIKTI), through the scholarship of Program Magister menuju Doktor untuk Sarjana Unggul (PMDSU) with contract number 5839/ UN1.DITLIT/DIT-LIT/LT/2018 for the financial support during the research and preparation of this manuscript.

\section{CONFLICT OF INTEREST}

The authors declare that they have no conflicts of interest in this work.

\section{ETHICAL APPROVAL}

This study does not involve the use of animals or human subjects.

\section{AUTHOR CONTRIBUTIONS}

All authors made substantial contributions to conception and design, acquisition of data, or analysis and interpretation of data; took part in drafting the article or revising it critically for important intellectual content; agreed to submit to the current journal; gave final approval of the version to be published; and agree to be accountable for all aspects of the work. All the authors are eligible to be an author as per the international committee of medical journal editors (ICMJE) requirements/guidelines.

\section{PUBLISHER'S NOTE}

This journal remains neutral with regard to jurisdictional claims in published institutional affiliation.

\section{REFERENCES}

Abbasi E, Nassiri-Asl M, Sheikhi M, Shafiee M. Effects of vitexin on scopolamine-induced memory impairment in rats. Chin J Physiol, 2013; 56(3):184-9.

Abushakra S, Porsteinsson A, Scheltens P, Sadowsky C, Vellas B, Cummings J, Gauthier S, Hey JA, Power A, Wang P, Shen L, Tolar M. Clinical effects of tramiprosate in APOE4/4 homozygous patients with mild Alzheimer's disease suggest disease modification potential. J Prev Alzheimers Dis, 2017; 4:149-56.

Achilonu MC, Dennis OU. Bioactive phytochemicals: bioactivity, sources, preparations and/or modifications via silver tetrafluoroborate mediation. J Chem, 2015; 2015:1-22.

Adams PW, Adejare A, Adeniji AO, Alamri M, Ates-Alagoz Z, Barrett JE, Caito SW, Camacho JB, Carlson E, Colestock T, Corum E, Finn LA, Glenn M, Hu DD, Hu C, Khalaj S, Mace L, McGonigle P, Mody VV, Moelter ST, Mondragón-Rodríguez S, Newell-Caito JL, Peña-Ortega F, Perry G, Sheerin M, Taghibiglou C, Valasani KR, Vangavaragu JR, Wallach J, Yacoubian TA, Yan SSD. Drug discovery approaches for the treatment of neurodegenerative disorders: Alzheimer's disease. Elsevier, San Diego, CA, 2017

Alber J. Pathophysiologic relationship between Alzheimer's disease, cerebrovascular disease, and cardiovascular risk : a review and synthesis. Alzheimer's Dement Diagn Assess Dis Monit, 2017; 7:69-87.

Balmus IM, Ciobica A. Main plant extracts' active properties effective on scopolamine-induced memory loss. Am J Alzheimers Dis Other Demen, 2017; 32(7):418-28.

Benek O, Jan K, Ondrej S. A perspective on multi-target drugs for Alzheimer's disease. Trends Pharmacol Sci, 2020; 41(7):434-45.

Bizzarri M, Giuliani A, Monti N, Verna R, Pensotti A, Cucina A. Rediscovery of natural compounds acting via multitarget recognition and noncanonical pharmacodynamical actions. Drug Discov Today, 2020; 25(5):920-7.

Blokland A, Anke S, Jos P, Wim JR. Why an M1 antagonist could be a more selective model for memory impairment than scopolamine? Front Neurol, 2016; 7(167):10-3.

Brodowska KM. Natural flavonoids: classification, potential role, and application of flavonoid analogues. Eur J Biol Res, 2017; 7(2):108-23.

Budzynska B, Boguszewska-Czubara A, Kruk-Slomka M, Skalicka-Wozniak K, Michalak A, Musik I, Biala G. Effects of imperatorin 
on scopolamine-induced cognitive impairment and oxidative stress in mice. Psychopharmacology, 2015; 232(5):931-42.

Chen X, Decker M. Multi-target compounds acting in the central nervous system designed from natural products. Curr Med Chem, 2013; 20(13):1673-85.

Cheng LL, Chen XN, Wang Y, Yu L, Kuang X, Wang LL, Yang $\mathrm{W}, \mathrm{Du}$ JR. Z-ligustilide isolated from radix angelicae sinensis ameliorates the memory impairment induced by scopolamine in mice. Fitoterapia, 2011; 82(7):1128-32.

Colizzi C. The protective effects of polyphenols on Alzheimer's disease: a systematic review. Alzheimer's Dement Transl Res Clin Interv, 2019; 5:184-96.

Dalli T, Merve B, Sule TU, Fahri A, Birsen E. Thymoquinone activates MAPK pathway in hippocampus of streptozotocin-treated rat model. Biomed Pharmacother, 2018; 99:391-401.

De Andrade Teles RB, Diniz TC, Pinto TCC, de Oliveira Júnior RG, Silva MGE, de Lavor ÉM, Fernandes AWC, de Oliveira AP, de Almeida Ribeiro FPR, da Silva AAM, Cavalcante TCF, Júnior LJQ, da Silva Almeida JRG. Review article flavonoids as therapeutic agents in Alzheimer's and parkinson's diseases: a systematic review of preclinical evidences. Oxid Med Cell Longev, 2018; 2018:1-21.

Deture MA, Dennis WD. The neuropathological diagnosis of Alzheimer's disease. Mol Neurodegener, 2019; 14(1):1-18.

Dhingra D, Varun K. Memory-enhancing activity of palmatine in mice using elevated plus maze and morris water maze. Adv Pharmacol Sci, 2012; 2012:1-7.

Elibol B, Sule TU, Merve B, Cigdem S. Thymoquinone (TQ) demonstrates its neuroprotective effect via an anti-inflammatory action on the $A \beta_{(1-42)}$-infused rat model of Alzheimer's disease. Psychiatry Clin Psychopharmacol, 2019; 29(4):379-86.

Fard MT, Con S. A review and hypothesized model of the mechanisms that underpin the relationship between inflammation and cognition in the elderly. Front Aging Neurosci, 2019; 11(3):1-22.

Ferreira-Vieira TH, Guimaraes IM, Silva FR, Ribeiro FM. Alzheimer's disease: targeting the cholinergic system. Curr Neuropharmacol, 2016; 14(1):101-15.

Gacar N, Mutlu O, Utkan T, Celikyurt IK, Gocmez SS, Ulak G. Beneficial effects of resveratrol on scopolamine but not mecamylamine induced memory impairment in the passive avoidance and morris water maze tests in rats. Pharmacol Biochem Behav, 2011; 99(3):316-23.

Giridharan VV, Thandavarayan RA, Sato S, Ko KM, Konishi T. Prevention of scopolamine-induced memory deficits by schisandrin B, an antioxidant lignan from schisandra chinensis in mice. Free Radic Res, 2011; 45(8):950-8.

Guo C, Shen J, Meng Z, Yang X, Li F. Neuroprotective effects of polygalacic acid on scopolamine-induced memory deficits in mice. Phytomedicine, 2016; 23(2):149-55.

Haider S, Tabassum S, Perveen T. Scopolamine-induced greater alterations in neurochemical profile and increased oxidative stress demonstrated a better model of dementia: a comparative study. Brain Res Bull, 2016; 127:234-47.

Hampel H, Mesulam M, Claudio CA, Martin RF, Ezio G, George TG, Khachaturian AS, Vergallo A, Cavedo E, Snyder PJ, Khachaturian ZS. The cholinergic system in the pathophysiology and treatment of Alzheimer's disease. Brain, 2020; 141(7):1917-33.

Harrison FE, Hosseini AH, Dawes SM, Weaver S, May JM. Ascorbic acid attenuates scopolamine-induced spatial learning deficits in the water maze. Behav Brain Res, 2009; 205(2):550-8.

He D, Wu H, Wei Y, Liu W, Huang F, Shi H, Zhang B, Wu X, Wang C. Effects of harmine, an acetylcholinesterase inhibitor, on spatial learning and memory of APP/PS1 transgenic mice and scopolamineinduced memory impairment mice. Eur J Pharmacol, 2015; 768:96-107.

Heidari S, Mehri S, Hosseinzadeh H. Memory enhancement and protective effects of crocin against d-galactose aging model in the hippocampus of Wistar rats. Iran J Basic Med Sci, 2017; 20(11):1250-9.

Hermann AMM. The case of galantamine: repurposing and late blooming of a cholinergic drug. Future Sci OA, 2015; 1(4):FSO73.
Hong SW, Yang JH, Joh EH, Kim HJ, Kim DH. Gypenoside TN-2 ameliorates scopolamine-induced learning deficit in mice. J Ethnopharmacol, 2011; 134(3):1010-3.

Imbimbo, BP, Solfrizzi V, Panza F. Are NSAIDs useful to treat Alzheimer's disease or mild cognitive impairment? Front Aging Neurosci, 2010; 2(19):1-14

Ishola IO, Adamson FM, Adeyemi OO. Ameliorative effect of kolaviron, a biflavonoid complex from garcinia kola seeds against scopolamine-induced memory impairment in rats: role of antioxidant defense system. Metab Brain Dis, 2017; 32(1):235-45.

Jafarian S, King HL, Zurina H, Lua PL, Mohd RS, Enoch KP. Effect of zerumbone on scopolamine-induced memory impairment and anxiety-like behaviours in rats. Alzheimer's Dement Transl Res Clin Interv, 2019; 5:637-43.

Jivad N, Rabiei Z. Study on medicinal plants used in the treatment of learning and memory impairments. Asian Pac J Trop Biomed, 2014; 4(10):780-9.

Johansson MM, Jan M, Ewa W. Cognitive impairment and its consequences in everyday life: experiences of people with mild cognitive impairment or mild. Int Psychogeriatrics, 2015; 2:1-10.

Jung IH, Se EJ, Eun HJ, Jayong C, Myung JH, Dong HK. Lancemaside a isolated from codonopsis lanceolata and its metabolite echinocystic acid ameliorate scopolamine-induced memory and learning deficits in mice. Phytomedicine, 2012; 20(1):84-8.

Jung K, Lee B, Han SJ, Ryu JH, Kim DH. Mangiferin ameliorates scopolamine-induced learning deficits in mice. Biol Pharm Bull, 2009; 32(2):242-6.

Kaur R, Mehan S. Ameliorative treatment with ellagic acid in scopolamine induced Alzheimer's type memory and cognitive dysfunctions in rats. Austin J Clin Neurol, 2015; 2(6):1-11.

Kent SA, Spires-Jones TL, Durrant CS. The physiological roles of tau and A $\mathrm{B}$ : implications for Alzheimer's disease pathology and therapeutics. Acta Neuropathol, 2020; 140(4):417-47.

Kim DH, Hung TM, Bae KH, Jung JW, Lee S, Yoon BH, Cheong JH, Ko KH, Ryu JH. Gomisin a improves scopolamine-induced memory impairment in mice. Eur J Pharmacol, 2006; 542(1-3):129-35.

Kim DH, Hyun SK, Yoon BH, Seo JH, Lee KT, Cheong JH, Jung SY, Jin C, Choi JS, Ryu JH. Gluco-obtusifolin and its aglycon, obtusifolin, attenuate scopolamine-induced memory impairment. J Pharmacol Sci, 2009b; 111(2):110-6.

Kim DH, Jeon SJ, Jung JW, Lee S, Yoon BH, Shin BY, Son KH, Cheong JH, Kim YS, Kang SS, Ko KH, Ryu JH. Tanshinone congeners improve memory impairments induced by scopolamine on passive avoidance tasks in mice. Eur J Pharmacol, 2007e; 574(2-3):140-7.

Kim DH, Jeon SJ, Son KH, Jung JW, Lee S, Yoon BH, Lee JJ, Cho YW, Cheong JH, Ko KH, Ryu JH. The ameliorating effect of oroxylin a on scopolamine-induced memory impairment in mice. Neurobiol Learn Mem, 2007d; 87(4):536-46.

Kim DH, Kim DY, Kim YC, Jung JW, Lee S, Yoon BH, Cheong JH, Kim YS, Kang SS, Ko KH, Ryu JH. Nodakenin, a coumarin compound, ameliorates scopolamine-induced memory disruption in mice. Life Sci, 2007c; 80(21):1944-50.

Kim E, Ko HJ, Jeon SJ, Lee S, Lee HE, Kim HN, Woo ER, Ryu $\mathrm{JH}$. The memory-enhancing effect of erucic acid on scopolamine-induced cognitive impairment in mice. Pharmacol Biochem Behav, 2016a; 142:85-90.

Kim EJ, Jung IH, Van Le TK, Jeong JJ, Kim NJ, Kim DH. Ginsenosides Rg5 and Rh3 protect scopolamine-induced memory deficits in mice. J Ethnopharmacol, 2013; 146(1):294-9.

Kim HJ, Eun-Joo S, Byung-Hwan L, Sun-Hye C, Seok-Won J, Ik-Hyun C, Hwang SH, Kim JY, Han JS, Chung C, Jang CG, Rhim H, Kim HC, Nah SY. Oral administration of gintonin attenuates cholinergic impairments by scopolamine, amyloid $\beta$ protein, and mouse model of alzheimer's disease. Mol Cells, 2015; 38(9):796-805.

Kim MJ, Choi SJ, Lim ST, Kim HK, Heo HJ, Kim EK, Jun WJ, Cho HY, Kim YJ, Shin DH. Ferulic acid supplementation prevents trimethyltin-induced cognitive deficits in mice. Biosci Biotechnol Biochem, 2007b; 71(4):1063-8. 
Kim S, Kim DH, Choi JJ, Lee JG, Lee CH, Park SJ, Jung WY, Park DH, Ko KH, Lee SH, JH, Ryu SH. Forsythiaside, a constituent of the fruits of forsythia suspense, ameliorates scopolamine-induced memory impairment in mice. Biomol Ther, 2009a; 17(3):249-55.

Kim S, Min-Soo K, Kwanghoon P, Hyeon-Joong K, Seok-Won J, Seung-Yeol N, Han JS, Chung CH. Hippocampus-dependent cognitive enhancement induced by systemic gintonin administration. J Ginseng Res, $2016 b ; 40: 55-61$.

Kinney JW, Shane MB, Andrew SM, Amanda ML, Arnold MS, Bruce TL. Inflammation as a central mechanism in Alzheimer's disease. Alzheimer's Dement Transl Res Clin Interv, 2018; 4:575-90.

Kumar S, Abhay KP. Chemistry and biological activities of flavonoids: an overview. Sci World J, 2013; 2013:1-16.

Kunle OF, Egharevba HO, Ahmadu PO. Standardization of herbal medicines-a review. Int J Biodivers Conserv, 2012; 4(3):101-12.

Kwon SH, Kim HC, Lee SY, Jang CG. Loganin improves learning and memory impairments induced by scopolamine in mice. Eur J Pharmacol, 2009; 619(1-3):44-9.

Lautie E, Olivier R, Pierre D, Jean AB, Salvatore S. Unraveling plant natural chemical diversity for drug discovery purposes. Front Pharmacol, 2020; 11(4): 1-37.

Lee GY, Lee C, Park GH, Jang JH. Amelioration of scopolamineinduced learning and memory impairment by $\alpha$-pinene in $\mathrm{C} 57 \mathrm{BL} / 6$ mice. Evid Based Complement Alternat Med, 2017; 2017:1-9.

Lee KY, Jeong EJ, Lee HS, Kim YC. Acteoside of callicarpa dichotoma attenuates scopolamine-induced memory impairments. Biol Pharm Bull, 2006; 29(1):71-4.

Lee S, Kim J, Seo SG, Choi BR, Han JS, Lee KW, Kim J. Sulforaphane alleviates scopolamine-induced memory impairment in mice. Pharmacol Res, 2014; 85:23-32.

Lee Y, J Kim J, Jang S, Oh S. Administration of phytoceramide enhances memory and upregulates the expression of pCREB and BDNF in hippocampus of mice. Biomol Ther, 2013; 21(3):229-33.

Li W, Sun L, Xiao S. Prevalence, incidence, influence factors, and cognitive characteristics of amnestic mild cognitive impairment among older adult: a 1-year follow-up study in china. Front Psychiatry, 2020; 11(2):1-9.

Liu H, Junjian Z. Cerebral hypoperfusion and cognitive impairment: the pathogenic role of vascular oxidative stress. Int J Neurosci, 2012; 122(9):494-9.

Liu J, Yu H, Ning X. Effect of quercetin on chronic enhancement of spatial learning and memory of mice. Sci China C Life Sci, 2006; 49(6):583-90.

Lu C, Yan W, Teng X, Qi L, Donghui W, Lijing Z, Fan B, Wang F, Liu X. Genistein ameliorates scopolamine-induced amnesia in mice through the regulation of the cholinergic neurotransmission, antioxidant system and the ERK/CREB/BDNF signaling. Front Pharmacol, 2018; 9:1-11.

Mansouri MT, Farbood Y, Naghizadeh B, Shabani S, Mirshekar MA, Sarkaki A. Beneficial effects of ellagic acid against animal models of scopolamine- and diazepam-induced cognitive impairments. Pharm Biol, 2016; 54(10):1947-53.

Mehta M, Abdu A, Marwan S. New acetylcholinesterase inhibitors for Alzheimer's disease. Int J Alzheimers Dis, 2012; 2012:1-8.

Moss DE. Improving anti-neurodegenerative benefits of acetylcholinesterase inhibitors in Alzheimer's disease: are irreversible inhibitors the future? Int J Mol Sci, 2020; 21(3438):1-18.

Mufson EJ, Binder L, Counts SE, DeKosky ST, deToledoMorrell L, Ginsberg SD, Ikonomovic MD, Perez SE, Scheff SW. Mild cognitive impairment: pathology and mechanisms. Acta Neuropathol, 2012; 123(1):13-30.

Ohta H, Kinzo M, Hiroshi W, Mineo S. Involvement of $\beta 1$ but not $\beta 2$-adrenergic systems in the antagonizing effect of paeoniflorin on scopolamine-induced deficit in radial maze performance in rats. Jpn $\mathrm{J}$ Pharmacol, 1993; 62(2):199-202.

Oskouei Z, Soghra M, Fatemeh K, Hossein H. Evaluation of the effect of thymoquinone in d-galactose-induced memory impairments in rats: role of MAPK, oxidative stress, and neuroinflammation pathways and telomere length. Phytother Res, 2020; 35(4): 2252-2266.

Oxford AE, Erica SS, Troy TR. Clinical trials in Alzheimer's disease: a hurdle in the path of remedy. Int J Alzheimers Dis, 2020; 2020:1-13.

Park DH, Park SJ, Kim JM, Jung WY, Ryu JH. Subchronic administration of rosmarinic acid, a natural prolyl oligopeptidase inhibitor, enhances cognitive performances. Fitoterapia, 2010; 81(6):644-8.

Park SJ, Ahn YJ, Oh SR, Lee Y, Kwon G, Woo H, Lee HE, Jang DS, Jung JW, Ryu JH. Amyrin attenuates scopolamine-induced cognitive impairment in mice. Biol Pharm Bull, 2014; 37(7):1207-13.

Park SJ, Kim DH, Jung JM, Kim JM, Cai M, Liu X, Hong JG, Lee $\mathrm{CH}$, Lee KR, Ryu JH. The ameliorating effects of stigmasterol on scopolamine-induced memory impairments in mice. Eur J Pharmacol, 2012; 676(1-3):64-70.

Parle M, Dinesh D. Ascorbic acid: a promising memoryenhancer in mice. J Pharm Sci, 2003; 93(2):129-35.

Peng WH, Hsieh MT, Wu CR. Effect of long-term administration of berberine on scopolamine-induced amnesia in rats. Jpn J Pharmacol, 1997; 74(3):261-6.

Prashar Y, Gill NS, Kakkar S. A review on medicinal plants affecting amnesia on scopolamine induced model. PharmaTutor Mag, 2014, 2(12):20-8

Rahimi R, Ghiasi S, Azimi H, Fakhari S, Abdollahi M. A review of the herbal phosphodiesterase inhibitors; future perspective of new drugs. Cytokine, 2010; 49(2):123-9.

Ramsay RR, Popovic-Nikolic MR, Nikolic K, Uliassi E, Bolognesi ML. A perspective on multi-target drug discovery and design for complex diseases. Clin Transl Med, 2018; 7(1):1-14.

Ratheesh G, Lingling T, Jayarama RV, Hariharan E, Asif S, Tai-Ping F, Ramakrishna S. Role of medicinal plants in neurodegenerative diseases. Biomanuf Rev, 2017; 2(2):1-6.

Richardson C, Stephan BCM, Robinson L, Brayne C, Matthews FE, Cognitive Function and Ageing Study Collaboration. Two-decade change in prevalence of cognitive impairment in the UK. Eur J Epidemiol, 2019; 34(11):1085-92.

Rizzi L, Idiane R, Matheus R. Global epidemiology of dementia: Alzheimer's and vascular types. Biomed Res Int, 2014; 2014:1-8.

Robertson LT. Memory and the brain. J Dent Educ, 2002; 66(1):30-42.

Saroj K, Tulika S. Docosahexaenoic acid administration ameliorates scopolamine-induced memory impairment in mice. Asian J Pharm Clin Res, 2018; 11(6):349-52.

Sharma D, Puri M, Tiwary AK, Singh N, Jaggi AS. Antiamnesic effect of stevioside in scopolamine-treated rats. Indian J Pharmacol, 2010; 42(3):164-7.

Sharma K. Cholinesterase inhibitors as Alzheimer's therapeutics (review). Mol Med Rep, 2019; 20(2):1479-87.

Shi J, Liu Q, Wang Y, Luo G. Coadministration of huperzine a and ligustrazine phosphate effectively reverses scopolamine-induced amnesia in rats. Pharmacol Biochem Behav, 2010; 96(4):449-53.

Stanciu GD, Luca A, Rusu RN, Bild V, Beschea Chiriac SI, Solcan C, Bild W, Ababei DC. Alzheimer's disease pharmacotherapy in relation to cholinergic system involvement. Biomolecules, 2019; 10(1):1-21.

Stuve O, Weideman RA, Danni MM, David AJ, Bertis BL. Diclofenac reduces the risk of Alzheimer's disease: a pilot analysis of NSAIDs in two us veteran populations. Ther Adv Neurol Disord, 2020; 13:1-11.

Sun Q, Xie N, Tang B, Li R, Shen Y. Alzheimer's disease: from genetic variants to the distinct pathological mechanisms. Front Mol Neurosci, 2017; 10:1-14

Tao L, Jianmei X, Yuting W, Shi W, Shuangchan W, Qiman W, Ding H. Protective effects of aloe-emodin on scopolamine-induced memory impairment in mice and $\mathrm{H}_{2} \mathrm{O}_{2}$-induced cytotoxicity in $\mathrm{PC} 12$ cells. Bioorg Med Chem Lett, 2014; 24(23):5385-9.

Tiwari S, Atluri V, Kaushik A, Yndart A, Nair M. Alzheimer's disease: pathogenesis, diagnostics, and therapeutics. Int J Nanomedicine, $2019 ; 14: 5541-54$ 
Tolar M, Susan A, Marwan S. The path forward in alzheimer's disease therapeutics: reevaluating the amyloid cascade hypothesis. Alzheimer Dement, 2020; 16:1553-60.

Tönnies E, Trushina E. Oxidative stress, synaptic dysfunction, and Alzheimer's disease. J Alzheimers Dis, 2017; 57(4):1105-21.

Wang B, Zhong Y, Gao C, and Li J. Myricetin ameliorates Scopolamine-induced memory impairment in mice via inhibiting acetylcholinesterase and down-regulating brain iron. Biochem Biophys Res Commun, 2017; 490(2):336-42.

Wang CM, Liu MY, Wang F, Wei MJ, Wang S, Wu CF, Yang JY. Anti-amnesic effect of pseudoginsenoside-F11 in two mouse models of Alzheimer's disease. Pharmacol Biochem Behav, 2013; 106:57-67.

Wang G, Chen L, Pan X, Chen J, Wang L, Wang W, Cheng R, Wu F, Feng X, Yu Y, Zhang HT, O'Donnell JM, Xu Y. The effect of resveratrol on beta amyloid-induced memory impairment involves inhibition of phosphodiesterase-4 related signaling. Oncotarget, 2016; 7(14):17380-92.

Wang $\mathrm{H}$, Wang $\mathrm{H}$, Cheng $\mathrm{H}$, Che Z. Ameliorating effect of luteolin on memory impairment in an Alzheimer's disease model. Mol Med Rep, 2016; 13(5):4215-20.

Xie Y, Zhao QY, Li HY, Zhou X, Liu Y, Zhang H. Curcumin ameliorates cognitive deficits heavy ion irradiation-induced learning and memory deficits through enhancing of Nrf2 antioxidant signaling pathways. Pharmacol Biochem Behav, 2014; 126:181-6.
Yaari R, Ann H. Alzheimer's disease clinical trials: past failures and future opportunities. Clin Trial Perspect, 2015; 5(3):297-309.

Yunqi X, Junqiang Y, Peng Z, Li J, Gao H, Xia Y, Wang Q. Neurotransmitter receptors and cognitive dysfunction in Alzheimer's disease and Parkinson's disease. Prog Neurobiol, 2013; 97(1):1-13.

Zhang L, Zhang Z, Fu Y, Yang P, Qin Z, Chen Y, Xu Y. Transcinnamaldehyde improves memory impairment by blocking microglial activation through the destabilization of iNos mRNA in mice challenged with lipopolysaccharide. Neuropharmacology, 2016; 110:503-18.

Zhu Z, Yan J, Jiang W, Yao XG, Chen J, Chen L, Li C, Hu L, Jiang $\mathrm{H}$, Shen $\mathrm{X}$. Arctigenin effectively ameliorates memory impairment in Alzheimer's disease model mice targeting both $\beta$-amyloid production and clearance. J Neurosci, 2013; 33(32):13138-49.

\section{How to cite this article:}

Helmi H, Fakhrudin N, Nurrochmad A, Ikawati Z. Plant natural products for cognitive impairment: A review of the preclinical evidence. J Appl Pharm Sci, 2021; 11(06):001-014. 


\section{GRAPHICAL ABSTRACT}
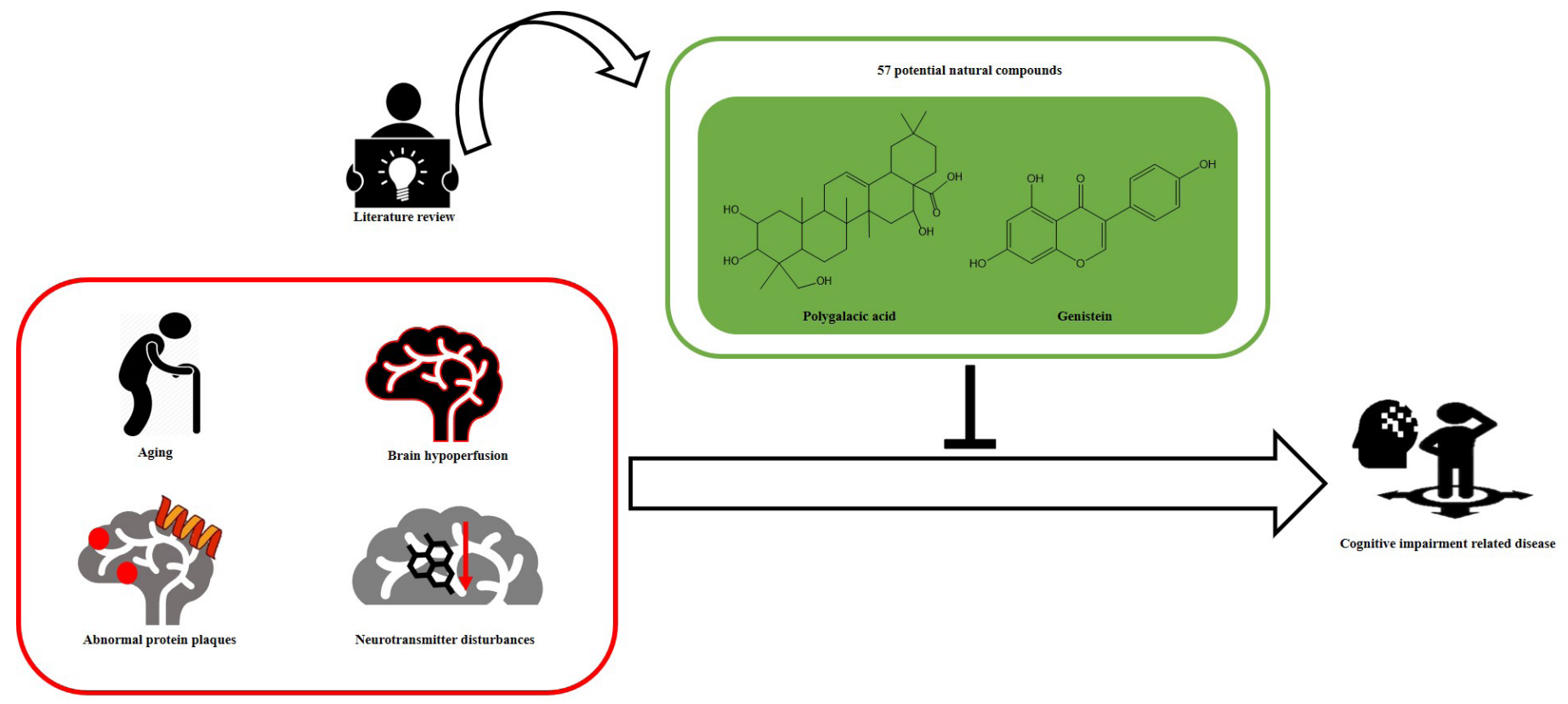